\title{
Cerium- and Iron-Oxide-Based Nanozymes in Tissue Engineering and Regenerative Medicine
}

\author{
Michelle M. T. Jansman $₫$ and Leticia Hosta-Rigau * \\ DTU Health Tech, Centre for Nanomedicine and Theranostics, Technical University of Denmark, \\ Produktionstorvet, B423, 2800 Kongens Lyngby, Denmark \\ * Correspondence: leri@dtu.dk; Tel.: +45-4525-8155
}

Received: 25 July 2019; Accepted: 12 August 2019; Published: 15 August 2019

check for updates

\begin{abstract}
Nanoparticulate materials displaying enzyme-like properties, so-called nanozymes, are explored as substitutes for natural enzymes in several industrial, energy-related, and biomedical applications. Outstanding high stability, enhanced catalytic activities, low cost, and availability at industrial scale are some of the fascinating features of nanozymes. Furthermore, nanozymes can also be equipped with the unique attributes of nanomaterials such as magnetic or optical properties. Due to the impressive development of nanozymes during the last decade, their potential in the context of tissue engineering and regenerative medicine also started to be explored. To highlight the progress, in this review, we discuss the two most representative nanozymes, namely, cerium- and iron-oxide nanomaterials, since they are the most widely studied. Special focus is placed on their applications ranging from cardioprotection to therapeutic angiogenesis, bone tissue engineering, and wound healing. Finally, current challenges and future directions are discussed.
\end{abstract}

Keywords: catalytic activity; cerium-oxide nanoparticles; iron-oxide nanoparticles; nanoparticles; nanozymes; reactive oxygen species; superparamagnetic nanoparticles; regenerative medicine; tissue engineering

\section{Introduction}

Over the past three decades, research efforts focused on mimicking the functionality and structural properties of biological enzymes [1]. The overall goal was to create "artificial enzymes" that mimic the key functions of naturally occurring enzymes, but also display enhanced properties such as improved stability or being more cost-efficient $[2,3]$. This is because the practical use of native enzymes is hampered by several limitations. Biological enzymes possess a very short half-life, display immunogenicity within our organism, and are highly sensitive to environmental changes [4]. As an example, the half-lives of nanozymes were reported to be as high as several days in contrast to several minutes for their biological counterparts [5-7]. Furthermore, they are obtained via direct synthesis or via extraction from natural organisms [1], which are accompanied by high production costs [8].

To the present day, various attempts to create "artificial enzymes" were reported, and include the development of metal complexes [9], polymers [10,11], supramolecular systems [12,13], and bio-molecules [14]. Of particular interest are inorganic nanoparticles (NPs) with enzyme-like properties, so-called "nanozymes". While inorganic NPs may seem very different from native enzymes, they share several features with their biological counterparts such as a similar size, an irregular shape, or a rich surface chemistry [4]. In addition, nanoparticulate enzyme mimics display much higher stability and large surface areas compared to biological enzymes [3]. Nanozymes, furthermore, exhibit a high number of catalytically active surface atoms, translating into high activities—oftentimes reacting in a more efficient manner than biological enzymes, which usually feature only one active site [1]. Additionally, nanozymes are available cost-efficiently and at an industrial scale. 
Despite having higher reactivity than biological enzymes, nanozymes display less specificity and selectivity [4]. However, such a drawback can be overcome if nanozymes are utilized for catalytic reactions involving small molecules (e.g., oxygen radicals or hydrogen peroxide $\left(\mathrm{H}_{2} \mathrm{O}_{2}\right)$ ), where the steric information of native enzymes has less relevance [4].

Nanozymes are mainly employed in environmental science and biomedicine [1,4], with the latter involving different areas ranging from cancer diagnostics to enzyme replacement, therapeutics for neurodegenerative disorders, and cancer or anti-bacterial therapy; the reader is referred to excellent and recent reviews in the field [4,15-18]. Recently, nanozymes are receiving increasing attention for tissue engineering applications, since initial biological studies highlighted their antioxidant protective effects in various cell lines [19-21].

In this review, we describe recent developments and future perspectives of nanoparticle enzyme mimics (so-called "nanozymes") in the field of tissue engineering and regenerative medicine. Despite a wide range of nanomaterials including carbon, metal, and metal oxide reporting catalytic activities [22], mainly metal oxides are explored in the context of regenerative medicine. An overview of the topics covered is shown in Scheme 1.

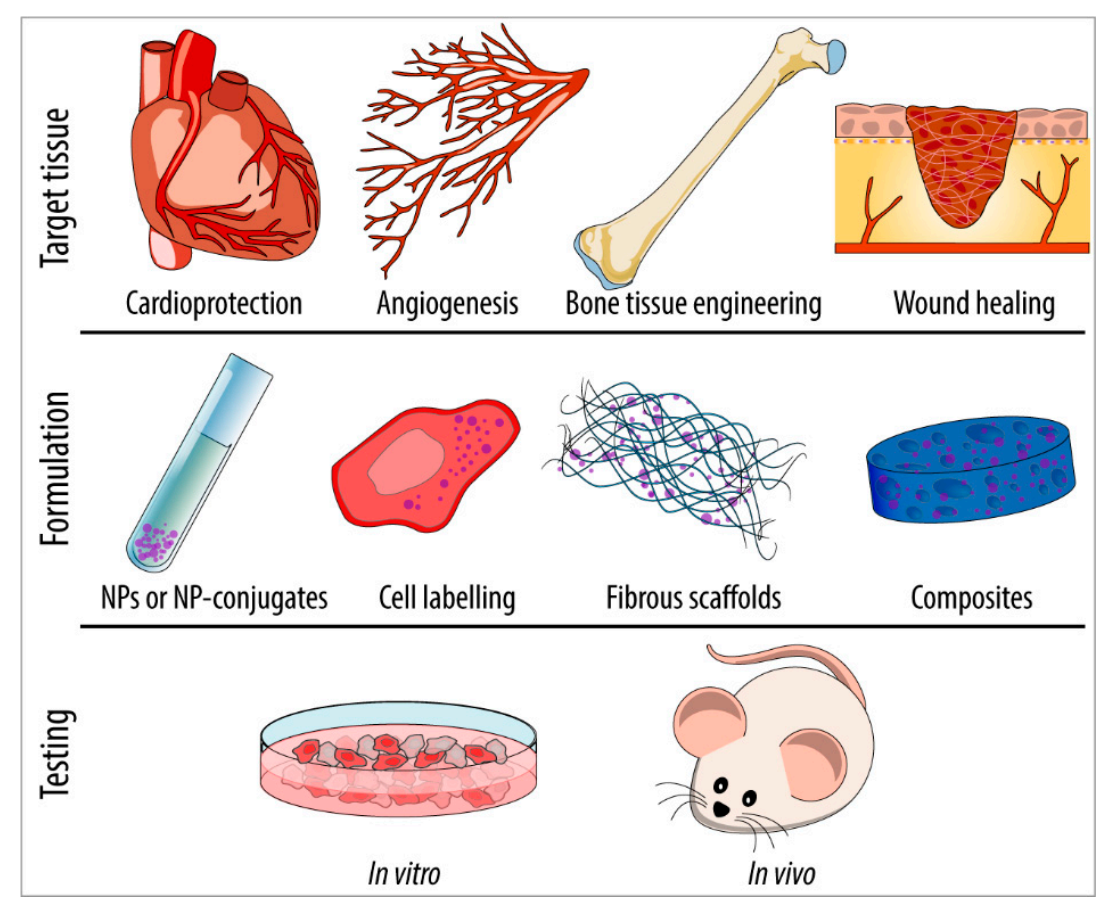

Scheme 1. Nanozymes are employed in the tissue engineering and regenerative medicine field with particular emphasis on cardioprotection, angiogenesis, bone tissue engineering, and wound healing. They are employed as nanoparticle (NPs) solutions or labeling agents for several mammalian cell lines, or incorporated within scaffolds such as fibrous networks or composites. Finally, they are evaluated in vitro and in vivo.

Efforts using metal oxides were mainly centered around cerium-oxide $\left(\mathrm{CeO}_{2}\right) \mathrm{NPs}(\mathrm{CO}-\mathrm{NPs})$ and iron-oxide NPs (IO-NPs), which mainly include hematite (iron(III) oxide, $\mathrm{Fe}_{2} \mathrm{O}_{3}$ ) and magnetite (iron(II, III) oxide, $\mathrm{Fe}_{3} \mathrm{O}_{4}$ ) NPs. This is due to the ability of both CO-NPs and IO-NPs to reduce reactive oxygen species (ROS) $[1,3,23]$. ROS are free-radical intermediates resulting from the conversion of oxygen into water $\left(\mathrm{H}_{2} \mathrm{O}\right)$, and consist of a superoxide anion radical $\left(\mathrm{O}_{2}{ }^{\bullet-}\right), \mathrm{H}_{2} \mathrm{O}_{2}$, and a hydroxyl radical $\left({ }^{\circ} \mathrm{OH}\right)(\mathrm{Scheme} 2 \mathrm{~A})$ [24]. Therefore, peroxidase- [25], catalase (CAT)- [26] and superoxide dismutase (SOD)-like activities were investigated [27]. The reduction reactions are showed in Scheme 2B where SOD catalyzes $\mathrm{O}_{2}{ }^{\bullet-}$ into $\mathrm{H}_{2} \mathrm{O}_{2}$, which can be subsequently catalyzed by CAT and peroxidase into $\mathrm{H}_{2} \mathrm{O}$. 


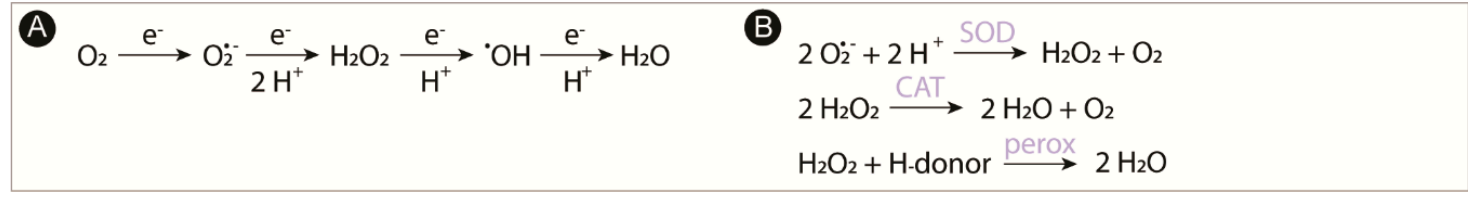

Scheme 2. The stepwise reduction of oxygen with its free radical intermediates (A). Enzymatic reactions of superoxide dismutase (SOD), catalase (CAT), and peroxidase (perox) to remove reactive oxygen species (B).

The antioxidant properties of CO-NPs are known to arise from the co-existence of Ce(III) and $\mathrm{Ce}(\mathrm{IV})$ oxidation states, which produce a redox couple responsible for their catalytic activity. Such a switch between the III/IV valence resembles the mechanism of redox enzymes, which use metals as co-factors to catalyze reversible redox reactions (Scheme 3) [21]. As such, reactions comprising redox cycles between $\mathrm{Ce}(\mathrm{III})$ and $\mathrm{Ce}(\mathrm{IV})$ oxidation states make it possible for CO-NPs to react catalytically with $\mathrm{O}_{2}{ }^{\bullet-}$ and $\mathrm{H}_{2} \mathrm{O}_{2}$, thus mimicking the function of two key antioxidant enzymes, namely, SOD and CAT (Scheme 3A,B, respectively) [21]. Upon reaction with $\mathrm{O}_{2}{ }^{\bullet-}, \mathrm{H}_{2} \mathrm{O}_{2}$ is formed while Ce(III) is oxidized to $\mathrm{Ce}(\mathrm{IV})$. Next, $\mathrm{Ce}(\mathrm{IV})$ reacts with $\mathrm{H}_{2} \mathrm{O}_{2}$ to generate oxygen while being reduced back to $\mathrm{Ce}(\mathrm{III})$. This regenerates the CO-NPs while eliminating both $\mathrm{O}_{2}{ }^{\bullet-}$ and $\mathrm{H}_{2} \mathrm{O}_{2}$ in a consecutive set of reactions. Alternatively, a second $\mathrm{H}_{2} \mathrm{O}_{2}$ molecule may get reduced into $\mathrm{H}_{2} \mathrm{O}$ while oxidizing Ce(III) into $\mathrm{Ce}(\mathrm{IV})$, thus acting as a true CAT mimic [21]. Therefore, CO-NPs could result as extraordinary antioxidants by scavenging two abundant ROS in a repetitive manner. Due to the ability to deplete ROS via a self-regenerating mechanism, CO-NPs, which are also biocompatible, were explored in the context of inflammation and pathologies associated with oxidative stress (e.g., neurodegenerative disorders or cancer) [21]. Naturally, such antioxidant properties were also explored in the context of regenerative medicine.
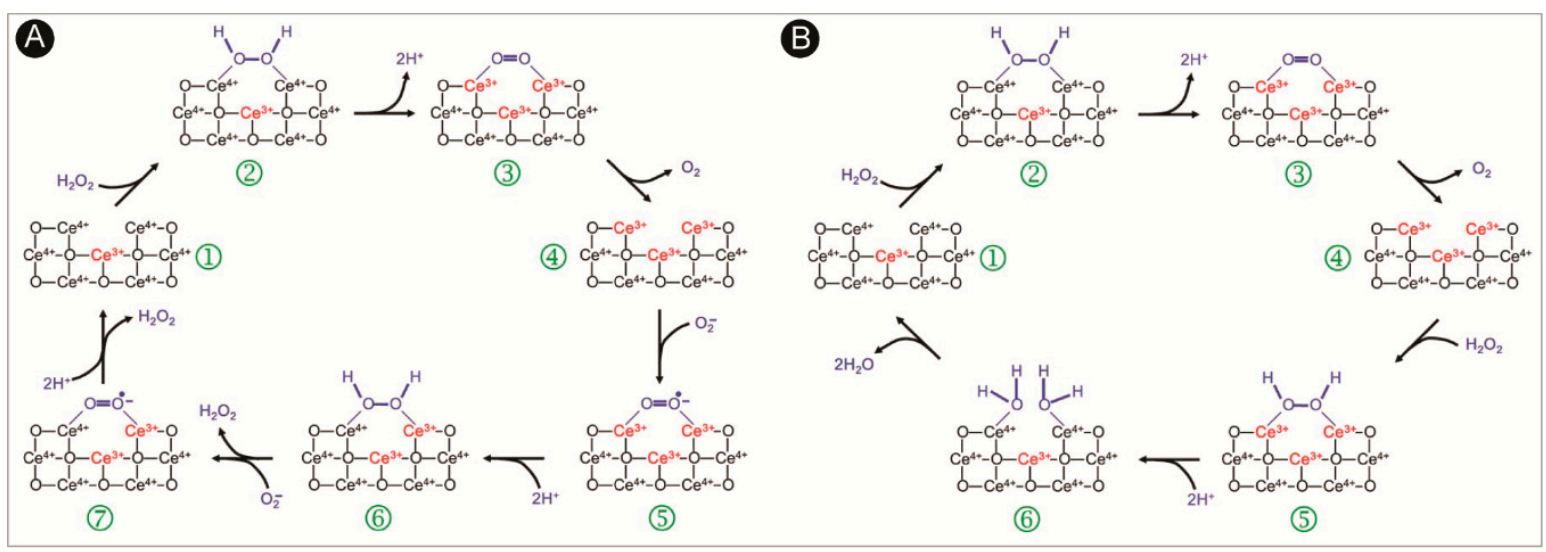

Scheme 3. The proposed mechanism for the enzymatic activity of cerium-oxide nanoparticles. Mechanism for superoxide dismutase activity (A) and catalase activity (B). The oxidative half-reactions (1-4) are identical in both reactions. Reprinted with permission from Reference [21]. Copyright 2011, Royal Society of Chemistry.

IO-NPs received tremendous attention due to their wide range of applications including electrochemical uses, data storage, or environmental remediation [28]. IO-NPs, due to their intrinsic magnetic properties (i.e., superparamagnetism) together with their biocompatibility and stability, also stand out of the crowd in the biomedical field [29]. In particular, due to their potential as contrast-enhancing probes for magnetic resonance imaging (MRI), IO-NPs are widely employed in diagnostics (e.g., detection, imaging, or biosensing) [30]. Additionally, IO-NPs also show enormous potential for therapeutic purposes such as hyperthermia, magnetic targeting, or drug delivery. IO-NPs can be used to generate local heat enhancement when submitted to an alternating magnetic field, 
a particularly efficient feature for the depletion of cancer cells which, in contrast to healthy cells, cannot survive in the temperature range of $42-49{ }^{\circ} \mathrm{C}$ [29,31]. Importantly, in 2007, it was reported that IO-NPs displayed intrinsic peroxidase-like activity similar to that of horseradish peroxidase (HRP) [32]. It was the first report of a nanozyme or inorganic nanoparticle performing as an enzyme mimic. Currently, IO-NPs also show the ability to mimic CAT-like activity. CAT, similar to HRP, belongs to the oxidoreductase family, and both enzymes contain a porphyrin heme group as a cofactor in their active site. The mechanisms behind the peroxidase and CAT activity are not fully understood, but it was proposed that Fenton/Haber-Weiss mechanisms are involved (Scheme 4) [33-35]. While both $\mathrm{Fe}_{2} \mathrm{O}_{3}$ and $\mathrm{Fe}_{3} \mathrm{O}_{4}$ NPs display HRP- and CAT-like activity, the latter display better activity than the former [36]. Thus, as a result of their antioxidant properties, IO-NPs were also recently reported in regenerative medicine and tissue engineering applications.

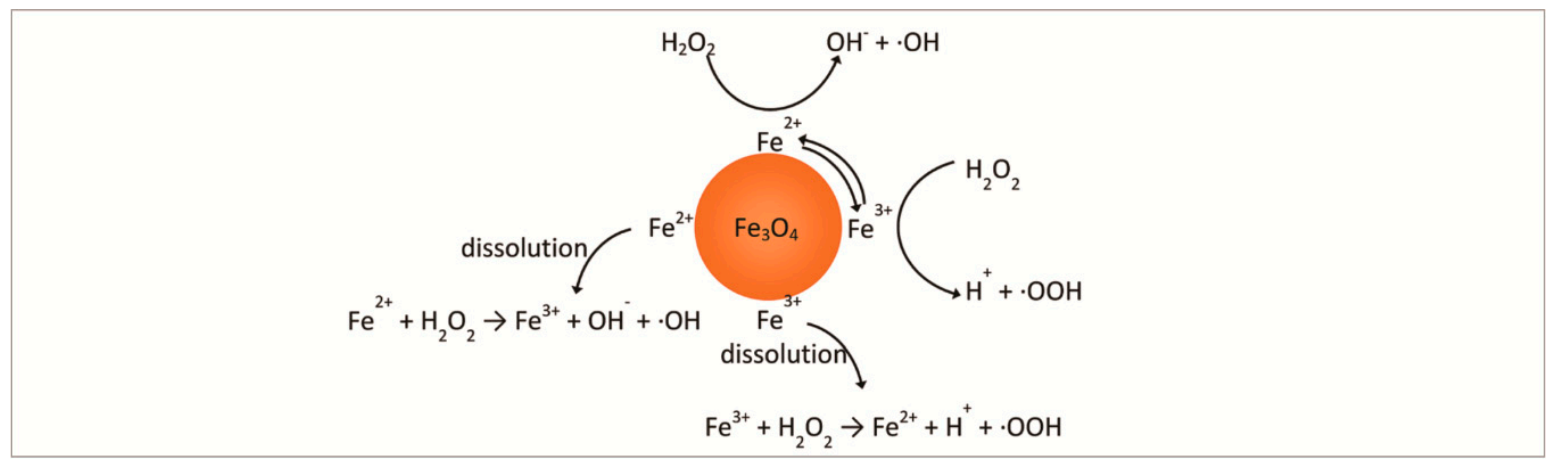

Scheme 4. The proposed mechanism for the enzymatic activity of iron-oxide $\left(\mathrm{Fe}_{3} \mathrm{O}_{4}\right)$ nanoparticles, including Fenton/Haber-Weiss reaction mechanisms. Reprinted with permission from Reference [33]. Copyright 2015, Royal Society of Chemistry.

\section{Nanozymes in Regenerative Medicine and Tissue Engineering}

\subsection{Cardioprotection}

A first example of the potential of CO-NPs for regenerative medicine was reported by the Kolattukudy group [20]. The authors reported the first research study where CO-NPs were employed to address stress-induced diseases in vivo. A transgenic mouse model with cardiac-specific expression of monocyte chemoattractant protein-1 (MCP-1) was used. MCP-1 is a pro-inflammatory cytokine which results in ischemic cardiomyopathy and activation of genes related to endoplasmic reticulum (ER) stress. It was shown that intravenously administered CO-NPs were able to inhibit the progression of left ventricular dysfunction and dilatation, and to decrease myocardial inflammation, pro-inflammatory cytokine expressions, and the expression of ER stress-associated genes. It was suggested that CO-NPs were able to block oxidative stress via their auto-regenerative antioxidant properties, thereby preventing inflammatory disorders [20]. In a follow-up study, the Kolattukudy group assessed the ability of CO-NPs to protect $\mathrm{H} 9 \mathrm{c} 2$ cardiomyocytes from oxidative damage induced by cigarette smoke extract [37]. Cigarette smoke contains and generates a large amount of ROS, overwhelming the antioxidant capacity of the heart, and leading to oxidative damage and the subsequent pathological consequences in the cardiovascular system. To evaluate the cardioprotection of CO-NPs, the authors employed an in vitro model where $\mathrm{H} 9 \mathrm{c} 2$ cardiomyocytes were exposed to cigarette smoke extracts. The amounts of ROS, nuclear factor- $\mathrm{kB}(\mathrm{NF}-\mathrm{kB})$, and inflammatory cytokines were analyzed. NF- $\mathrm{kB}$ is a redox-sensitive transcription factor that is activated by elevated ROS levels, and it is closely associated with myocardial inflammation, cardiac remodeling, and heart failure [38]. Pre-treatment with CO-NPs before exposure to cigarette smoke extract inhibited the depletion of critical antioxidant enzymes in vitro and diminished the levels of ROS, NF- $\mathrm{kB}$, and inflammatory cytokines [39].

Pre-treating cardiac cells with CO-NPs for oxidative stress protection was also investigated by Pagliari and co-workers [40]. Cardiac progenitor cells (CPCs) were harvested from mouse-derived 
hearts and treated with CO-NP for $24 \mathrm{~h}$. CPCs are highly relevant in regenerative medicine, since they have the potential to match the tissue demands of a damaged heart following myocardial infarction [41,42]. The in vitro culture of progenitor cells, however, requires the preservation of physiological ROS levels. By adding CO-NPs to the cell culture, the authors aimed to evaluate whether they could control the oxidative stress without harming the CPCs. The CO-NPs were floating in the cytosol, without affecting the cells' survival, growth, and capability to differentiate. Their antioxidant potential was demonstrated by exposing the cells to $\mathrm{H}_{2} \mathrm{O}_{2}$-induced oxidative stress in a dose- and time-dependent manner for up to seven days. The results showed $\sim 80 \%$ and $\sim 70 \%$ decreases in ROS levels for 25 and $10 \mu \mathrm{g} / \mathrm{mL}$ CO-NP, respectively. These results are of utmost interest, since they open the door to the creation of novel biomaterials such as CO-NP-loaded scaffolds that are able to create a beneficial microenvironment to preserve CPCs during in vitro tissue growth.

Another area of interest is the treatment of hypertension. Hypertension is associated with microvascular dysfunction, partially attributed to chronic inflammation and mitochondrial dysfunction, resulting in increased ROS levels [43-45]. The effect of CO-NPs acting as antioxidants was investigated using a spontaneously hypertensive rat model [43]. Characteristics of this rat model are its microvascular dysfunction and excess of local ROS production. After CO-NP exposure, the oxidative stress levels significantly decreased, being almost identical to those of a normotensive rat model that was not exposed to CO-NPs. Furthermore, analyzing pro-inflammatory cytokines in harvested plasma suggested that the CO-NPs altered the inflammatory signaling pathways in both rat models.

The Blough group investigated CO-NPs in a pulmonary arterial hypertension (PAH) model [46]. Since recent reports suggested that enhanced oxidative stress and apoptosis are related to the pathological remodeling of the heart, it was hypothesized that CO-NP administration would diminish oxidative stress and apoptosis. This fact would, in turn, attenuate PAH and right ventricular remodeling. PAH was induced in Sprague-Dawley rats via a single injection of the toxic compound monocrotaline (MCT), resulting in heart hypertrophy. Using pulsed-wave Doppler echocardiography, it was possible to show that administered CO-NPs were able to diminish the changes in pulmonary flow, right ventricular tissue weight, and wall thickness. The hypertrophic response to CO-NPs was also evaluated at a cellular level. In agreement with the echocardiographic findings, CO-NP administration promoted a decrease in strong indicators of PAH and right ventricular remodeling such as $\beta$-myosin heavy chain, fibronectin expression, protein nitrosylation, protein carbonylation, and cardiac superoxide levels. Since ventricular remodeling following PAH is related to cardiomyocyte apoptosis, the authors also verified the accompanying diminished caspase- 3 activation and reduction in serum inflammatory markers, which are all indicators of cardiomyocytes apoptosis.

The effect of CO-NPs in MCT-induced PAH was recently investigated in combination with mineralocorticoid receptor-antagonist spironolactone (SP), a diuretic used in chronic heart failure [47]. After treatment with $0.5 \mathrm{mg} / \mathrm{kg}$ CO-NPs, a one-fold reduction in $\mathrm{H}_{2} \mathrm{O}_{2}$, a 70\% reduction in ROS, and a $75 \%$ reduction in nitrites were observed (Figure 1A-C). Interestingly, the co-treatment with SP did not offer a significant additional effect on the cardiac oxidative stress. The authors also investigated changes in endothelin-1 (ET-1) levels. ET-1 is an endothelium-derived vasoconstrictor peptide present during pulmonary vasoconstriction, which is thought to play a role in the PAH pathogenesis [48]. Serum ET-1 levels increased nine-fold after PAH induction, and were reduced after CO-NP treatment (Figure 1D). A 59\% decrease was observed following administration of $0.5 \mathrm{mg} / \mathrm{kg}$ CO-NPs, whereas only a $21 \%$ decrease was present when combined with SP. Since the lungs are the major site for the production and clearance of ET-1 [49], the lung collagen content was assessed using hydroxyproline levels, showing $60 \%$ and $86 \%$ decreases for the single and co-treatments, respectively (Figure 1E). A lung tissue specimen furthermore showed only mild tissue affection for the CO-NP treatment (Figure 1F,G). It was hypothesized that the CO-NPs suppress the ET-1 system through their potent inhibitory effect on inflammatory mediators. The non-significant additive effect of co-treatment was thought to be due to the decreasing pulmonary vasoconstriction, without changing the pulmonary vascular histology caused by SP [50]. 

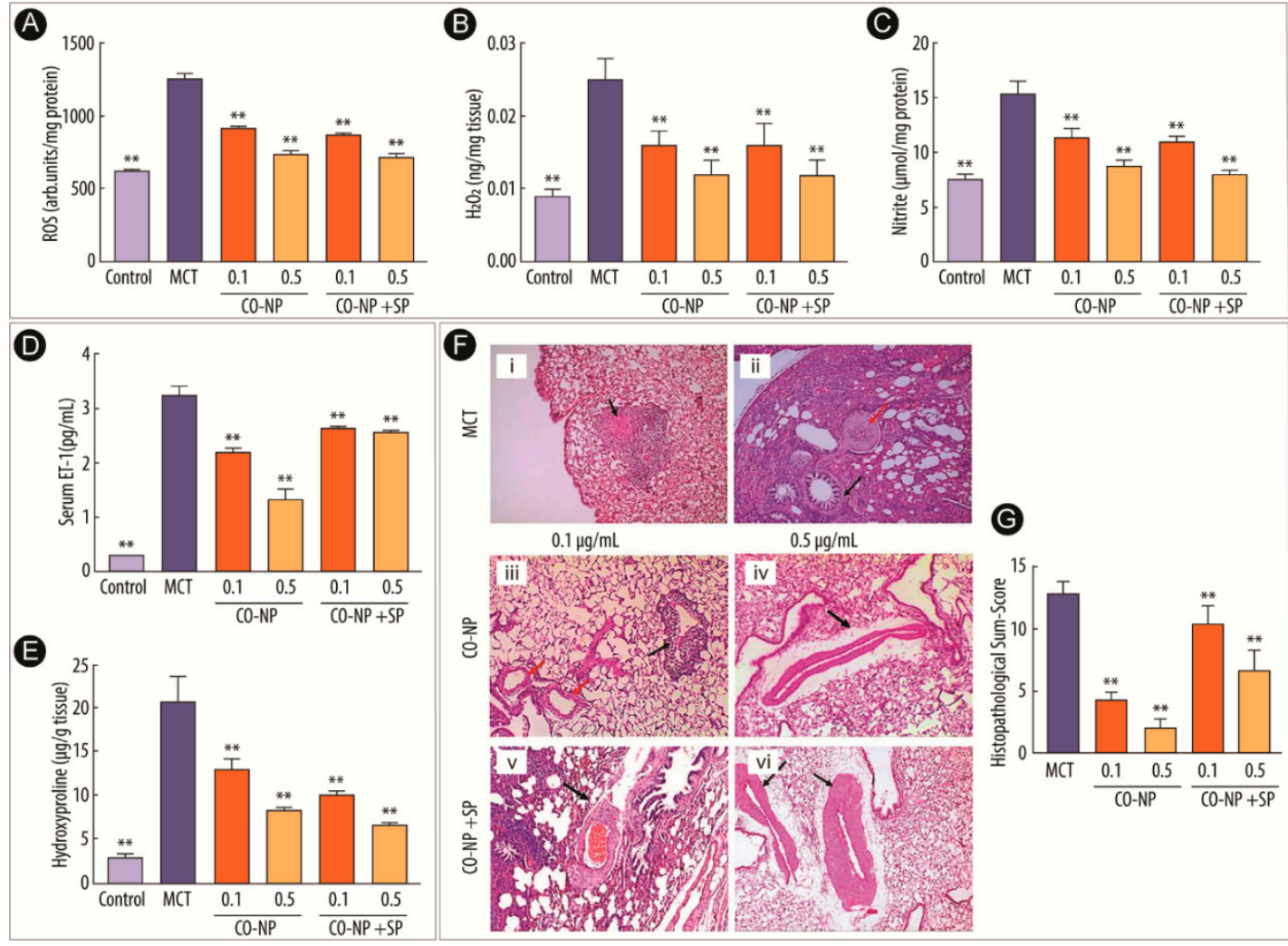

Figure 1. Cardioprotective effect of cerium-oxide nanoparticles (CO-NPs) in monocrotaline (MCT) rat model of pulmonary hypertension. The effect of 0.1 and $0.5 \mu \mathrm{g} / \mathrm{mL}$ CO-NPs \pm spironolactone (SP) on reactive oxygen species (ROS) (A), $\mathrm{H}_{2} \mathrm{O}_{2}$ (B), and nitrite (C) levels in right ventricular tissue. Effect of 0.1 and $0.5 \mu \mathrm{g} / \mathrm{mL}$ CO-NPs \pm SP on serum endothelin-1 (ET-1) (D) and lung hydroxyproline (E) levels. Hematoxylin and eosin (H\&E) staining of lung tissue after MCT injection (i, ii), and treatment with 0.1 and $0.5 \mu \mathrm{g} / \mathrm{mL}$ CO-NPs \pm SP (iii-vi) (F). 10× magnification. For further information and interpretation, the reader is referred to Reference [47]. Graphical presentation of the histopathological sum scores $(\mathbf{G}) ;{ }^{* *} p<0.001$ vs. MCT group. Reprinted with permission from Reference [47]. Copyright 2018, Elsevier Inc.

IO-NPs were also evaluated in a cardioprotection context. In a first study, IO-NPs were reported to protect hearts from ischemic damage both in vitro and in vivo [51]. Myocardial damage is often caused by a lack of blood flow to the heart, a dysfunction known as myocardial ischemia. This, in turn, leads to myocardial hypoxia which can then provoke coronary artery heart disease, angina pectoris, or even myocardial infarction [51]. At present, there is no proven effective therapy [52], and current treatment for myocardial ischemic injury involves the administration of several pharmaceutical drugs such as free-radical scavengers, antioxidants, calcium channel blockers, and anti-apoptotic agents [51]. However, one of the main concerns is that pharmacologic drugs target only one particular mechanism, while myocardial ischemic injury is associated with multiple pathological mechanisms. As an alternative approach, the cardioprotective potential of IO-NPs was evaluated. The IO-NPs were compared to the activity of two pharmaceutical drugs that are widely employed for the treatment of conditions involving myocardial ischemic injury-verapamil, which works as a calcium channel blocker, and Salvia miltiorrhiza extract, which acts as an antioxidant. The authors fabricated 2,3-dimercaptosuccinic acid (DMSA)-modified IO-NPs in a range of small sizes and evaluated their cardioprotective potential using a rat coronary artery ligature model [51]. The cardioprotective effect of the IO-NPs, which was assessed in terms of left ventricular developed pressure after ischemia reperfusion, was higher than that of both Salvia miltiorrhiza extract and verapamil. Interestingly, the cardioprotective effect was also shown to be dependent on the IO-NPs size, but independent of the surface charge. 
Han and co-workers employed IO-NPs to prime cardiac mesenchymal stem cells (cardiac MSCs, cMSCs) [53]. The multipotency of cMSCs is an encouraging feature; however, cardiac differentiation in vivo remains challenging [54-56]. Research efforts focused on inducing the cMSC cardiac phenotype in vitro by means of exogenous supplements (e.g., transforming growth factor beta 1 (TGF- $\beta 1$ ) or 5 -azacytidine), or by co-culturing them with cardiomyocytes or cardiomyoblasts $[57,58]$. While cMSCs co-culturing with $\mathrm{H} 9 \mathrm{c} 2$ cardiomyocytes showed promising results, $\mathrm{H} 9 \mathrm{c} 2$ cells hardly express the gap junction protein connexin 43 (Cx43) [59]. Cx43 is crucial for cMSC differentiation due to its central role in intercellular gap junction coupling and the subsequent cell-to-cell crosstalk in co-culture $[60,61]$. The authors pre-loaded the H9c2 cardiomyocytes with IO-NPs, which were subsequently co-cultured with cMSCs. It was hypothesized that, upon internalization by H9c2 cells, IO-NPs are partially ionized into iron ions, which then trigger the gap junctional signaling cascade. It was shown that IO-NP uptake enhanced the $\mathrm{Cx} 43$ expression in $\mathrm{H} 9 \mathrm{c} 2$, while also creating functional gap junction communications with the cMSCs. The cMSCs furthermore showed a significant increase in cardiac-specific genes which induced cardiac phenotype development. Next, the authors used the magnetic properties of the internalized IO-NPs to physically separate the H9c2 cells from the cMSCs (non-magnetic). The therapeutic efficacy of the differentiated cMSCs was evaluated by injecting them into myocardial infarction rat models. A reduced fibrotic tissue formation and superior infarct size suppression was observed. Transthoracic echocardiography furthermore showed a decrease in both left ventricular internal diameter at end diastole and at end systole for the cMSC group.

The group of Parivar used superparamagnetic IO-NPs to label the MSCs themselves [62]. Superparamagnetic IO-NPs are commonly used for cell tracking and as a contrast agent in MRI, and for magnetization of cells in tissue engineering and drug targeting [63,64]. Polyethylene glycol (PEG)ylated IO-NPs were synthesized and added to the MSCs for $48 \mathrm{~h}$ to obtain IO-NP-labeled MSCs. Next, the IO-NP-labeled MSCs were injected into the heart of a heart failure rat model. For the magnet-dependent IO-NP-labeled MSCs, a neodymium magnet was placed over the heart for $48 \mathrm{~h}$. A higher restoration of the injected fraction was observed in the magnetic-dependent group as compared to the unlabeled MSCs and the magnet-independent groups. Since a higher fraction of IO-NPs was retained in the heart, increased preservation of the cardiomyocytes was obtained, as well as a reduction in fibrosis formation after heart failure.

Finally, IO-NPs are also used in the context of cardioprotection to create scaffolds for heart tissue engineering applications. In particular, Mou and co-workers incubated DMSA-modified IO-NPs with primary cardiomyocytes, showing internalization in a dose-dependent manner without affecting cell viability [65]. While the internalized IO-NPs showed in vitro peroxidase-like activity able to decrease the ROS levels, no changes in Cx43 expression could be observed (Figure 2A,D). However, the results were different in a follow-up study by the same group [66]. This time, the DMSA-coated IO-NPs were supplemented to primary cardiomyocytes seeded on a collagen/Matrigel scaffold (Figure 2C). Interestingly, stronger contractions of the cell scaffolds were observed for the treatment groups. Such contractions are an indication of intercalated discs, which are composed of gap junctions, adherent junctions, and desmosomes between the cardiomyocytes [67]. This was confirmed using TEM, showing the presence of the different structures (Figure 2F). Western blotting showed increased expression of Cx43 in a dose-dependent manner, thus demonstrating the ability of IO-NPs in promoting gap junction assembly (Figure 2B,E). As such, these results show how different functions were exerted by the IO-NPs when comparing a two-dimensional (2D) environment [65] with a three-dimensional (3D) environment [66]. 

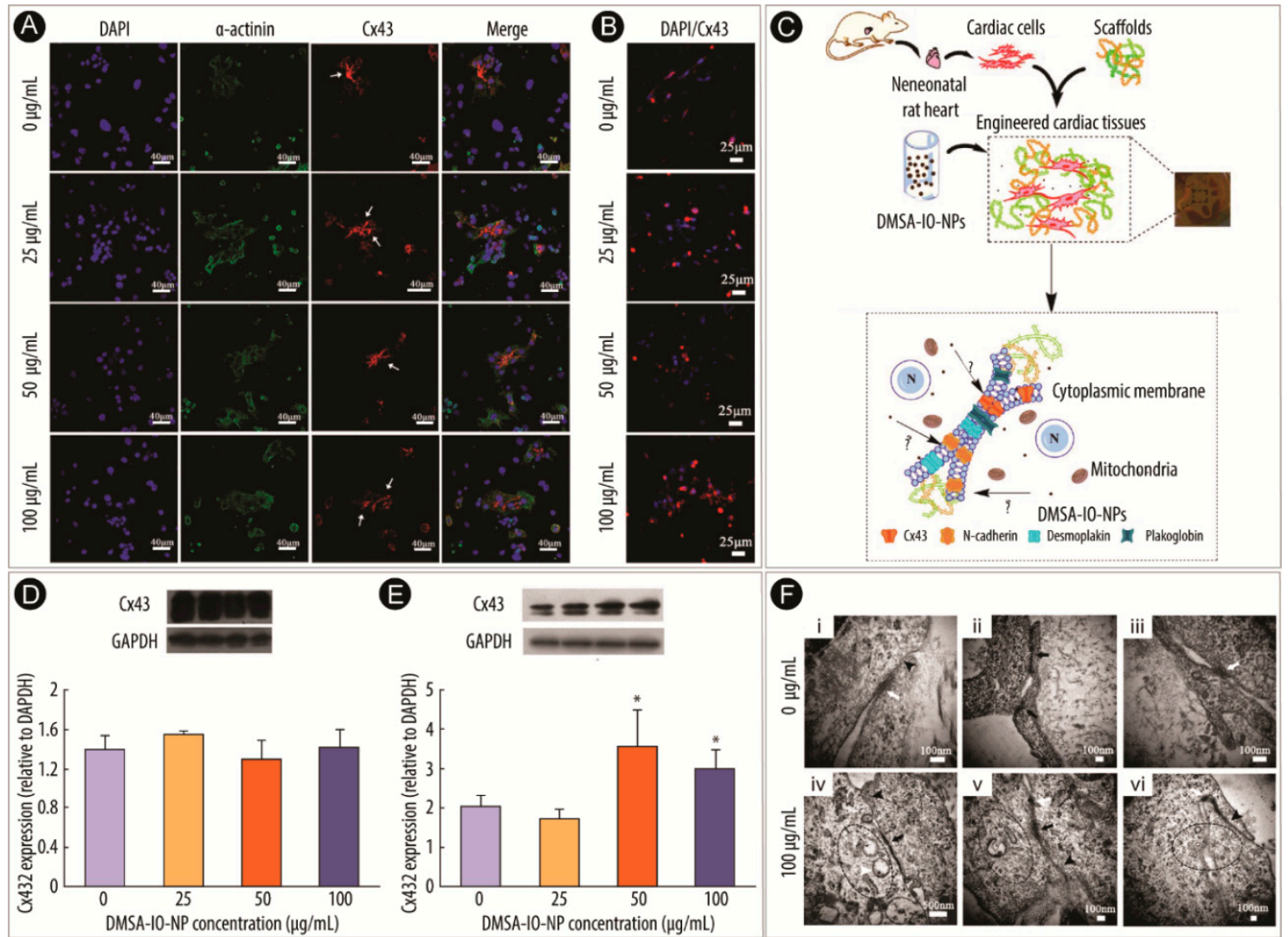

Figure 2. The effect of 2,3-dimercaptosuccinic acid-modified iron-oxide nanoparticles (DMSA-IO-NPs) in cardiac tissue engineering. Immunofluorescence staining of $\alpha$-actinin (green), connexin 43 (Cx43, red), and nuclei $\left(4^{\prime}, 6\right.$-diamidino-2-phenylindole (DAPI), blue) of cardiomyocytes under different concentrations of DMSA-IO-NP in a two-dimensional (2D) (A) and three-dimensional (3D) (B) culture. In (A), the arrows indicate the Cx43 distribution in cell-cell interfaces. Western blotting of Cx43 levels of cardiomyocytes under different concentrations of DMSA-IO-NP in a 2D (D) and 3D (E) culture, with glyceraldehyde 3-phosphate dehydrogenase (GAPDH) expression as an internal control; ${ }^{*} p<0.05$ vs. $0 \mu \mathrm{g} / \mathrm{mL}$. TEM imaging of gap junctions (black arrowhead), adherent junctions (white arrows), desmosomes (black arrows), and vesicle domain (dotted area) in the engineered cardiac tissues (ETCs) with different concentrations of DMSA-IO-NPs $(\mathbf{F})$. Schematic representation of the construction of ECTs and the evaluation of the effect of DMSA-IO-NPs on cardiomyocytes (C). For (A) and (D), reprinted with permission from Reference [65]. Copyright 2015, Royal Society of Chemistry. For (B,C,E,F), reprinted with permission from Reference [66]. Copyright 2016, John Wiley and Sons.

\subsection{Therapeutic Angiogenesis}

Angiogenesis, a process responsible for the formation of new blood vessels from existing ones, is a crucial phenomenon for several physiological and pathophysiological processes [68,69]. Therapeutic angiogenesis, which aims at promoting the formation of collateral vessels, is a novel and powerful strategy for treating patients suffering from severe ischemic diseases such as peripheral artery disease or myocardial infarction [70].

Currently, treatments to promote angiogenesis involve the administration of pro-angiogenic cytokines such as vascular endothelial growth factor (VEGF) and basic fibroblast growth factor (bFGF) [71,72]. However, clinical trials of growth factors including VEGF resulted in pathological angiogenesis, thrombosis, and fibrosis $[69,73,74]$. Another approach for therapeutic angiogenesis involves the transplantation of progenitor cells harvested from the bone marrow or circulating blood [75-77]. However, clinical trials of cell transplantation so far resulted in a very poor response [75-77]. 
Since novel approaches are highly sought after, nanozymes were also explored in the context of angiogenesis. Such approaches mainly rely on the protective antioxidant properties of nanozymes to modulate the intracellular oxygen environment which is closely related to angiogenesis.

In a pioneering study, CO-NPs were evaluated in terms of their pro-angiogenic potential using both in vitro and in vivo assays [69]. The authors took advantage of the oxygen-loading capacity of CO-NPs, which was attributed to the valence state of cerium combined with the inherent defects in the crystal lattice structure. The authors speculated that catalytically active CO-NPs would be able to modulate the intracellular oxygen environment within endothelial cells. This would result in endogenously stabilizing hypoxia-inducing factor $1 \alpha$ (HIF-1 $\alpha$ ), which would subsequently trigger angiogenesis. The authors engineered CO-NPs of different sizes (ranging from 5 to $60 \mathrm{~nm}$ ) and shapes including stars [78], polygonals [79], and nanorods [80]. Additionally, CO-NPs displaying two different $\mathrm{Ce}(\mathrm{III}) / \mathrm{Ce}(\mathrm{IV})$ ratios were considered and were termed CO-NP1 and CO-NP2 for high $\mathrm{Ce}(\mathrm{III})$ and high $\mathrm{Ce}(\mathrm{IV})$ content, respectively [69]. The different CO-NPs were pre-loaded in endothelial HUVECs (human umbilical vein endothelial cells), and the biocompatibility of the NPs was verified. Next, the anti- and pro-angiogenic effects were evaluated in vitro employing the endothelial tube formation assay [81]. The results, which demonstrated a significant and concentration-dependent induction of tube formation, were further confirmed in vivo. Via the chick chorioallantoic membrane (CAM) sprouting assays, it was possible to demonstrate $\sim 350 \%$ and a $\sim 250 \%$ angiogenic increases for CO-NP1 and CO-NP2, respectively, as compared to the untreated control. The authors were also able to demonstrate that angiogenesis was induced by a reduction of the intracellular ROS levels [82]. Interestingly, via Western blot, it was possible to estimate the amount of HIF-1 $\alpha$ within the cytoplasm and nucleus of the HUVECs. HIF- $1 \alpha$ regulates the tissue local oxygen concentrations [83], which then influence the angiogenic process. The results showed a higher amount of HIF- $1 \alpha$ for cells treated with CO-NP1 as compared to CO-NP2, thus demonstrating that the Ce(III)/Ce(IV) ratio in the CO-NPs plays a crucial role in angiogenesis. It was hypothesized that such a difference may be due to the fact that CO-NP1, due to the higher Ce(III) content, is highly deficient in oxygen and can, therefore, catalytically act as an oxygen buffer by providing facile pathways for the release and replenishment of intracellular oxygen. All in all, the authors were able to demonstrate the ability of CO-NPs to induce pro-angiogenesis, and that such an activity is critically dependent upon the surface valence states.

Further research on the relevance of the $\mathrm{Ce}(\mathrm{III}) / \mathrm{Ce}(\mathrm{IV})$ ratio was conducted by incorporating trivalent metal ions [84]. It was hypothesized that samarium (III) doping of CO-NPs (smCO-NPs) would allow tuning of the $\mathrm{Ce}(\mathrm{III}) / \mathrm{Ce}(\mathrm{IV})$ ratio in the NPs, thus enhancing the angiogenic potential of the NPs. The authors were able to demonstrate that smCO-NPs enhanced cell viability, proliferation, and expression of angiogenic markers (HIF- $1 \alpha$ and p38 mitogen-activated protein kinases) as compared to the non-doped controls.

CO-NPs were also incorporated in scaffolds for in situ tissue engineering. In situ tissue engineering does not incorporate cells into their materials, but rather utilizes the body's own regenerative capacity [85]. Polycaprolactone (PCL) scaffolds were fabricated by electrospinning, incorporating different percentages ( $w / w)$ of CO-NPs (PCL-CO-NPs) [86]. As shown in Figure 3A, highly porous networks of PCL-CO-NPs fibers were obtained. The biocompatibility of the composite scaffold was firstly evaluated in vitro using MSCs and HUVECs (Figure 3B). While the effect on MSCs was marginal, a more pronounced difference was observed for the HUVECs, showing overall enhanced viability for PLC-CO-NP-1\%. Next, analysis by means of CAM sprouting indicated increased angiogenesis for the CO-NP containing PLC scaffolds (Figure 3C). The number of capillary junctions was highest for PCL-CO-CP-1\%, with a 3.6-fold increase, while the blood vessel diameter was highest for both PCL-CO-CP-1\% and PCL-CO-CP-2\% (Figure 3D,E, respectively). Following on, the PCL-CO-NPs were subcutaneously implanted into male Sprague-Dawley rats showing better integration with the surrounding tissue as compared to bare PCL scaffolds. After one week of implantation, angiogenesis was observed for all scaffolds, with a positive correlation to the CO-NP content. The expressions of genes related to hypoxia, which are known to enhance cell proliferation and angiogenesis, were 
also investigated. The results demonstrated upregulation for both HIF- $1 \alpha$ and VEGF (Figure 3F,G, respectively), showing a dose-dependent hypoxia response. Since a significant inflammatory response for PCL-CO-CP-3\%, as shown by the upregulation of the inflammatory markers tumor necrosis factor $\alpha(\mathrm{TNF}-\alpha)$ and cyclooxygenase (COX), was observed (Figure 3H,I, respectively), it was concluded by the authors that the overall best properties were obtained when employing a CO-NP content $\leq 2 \%$.
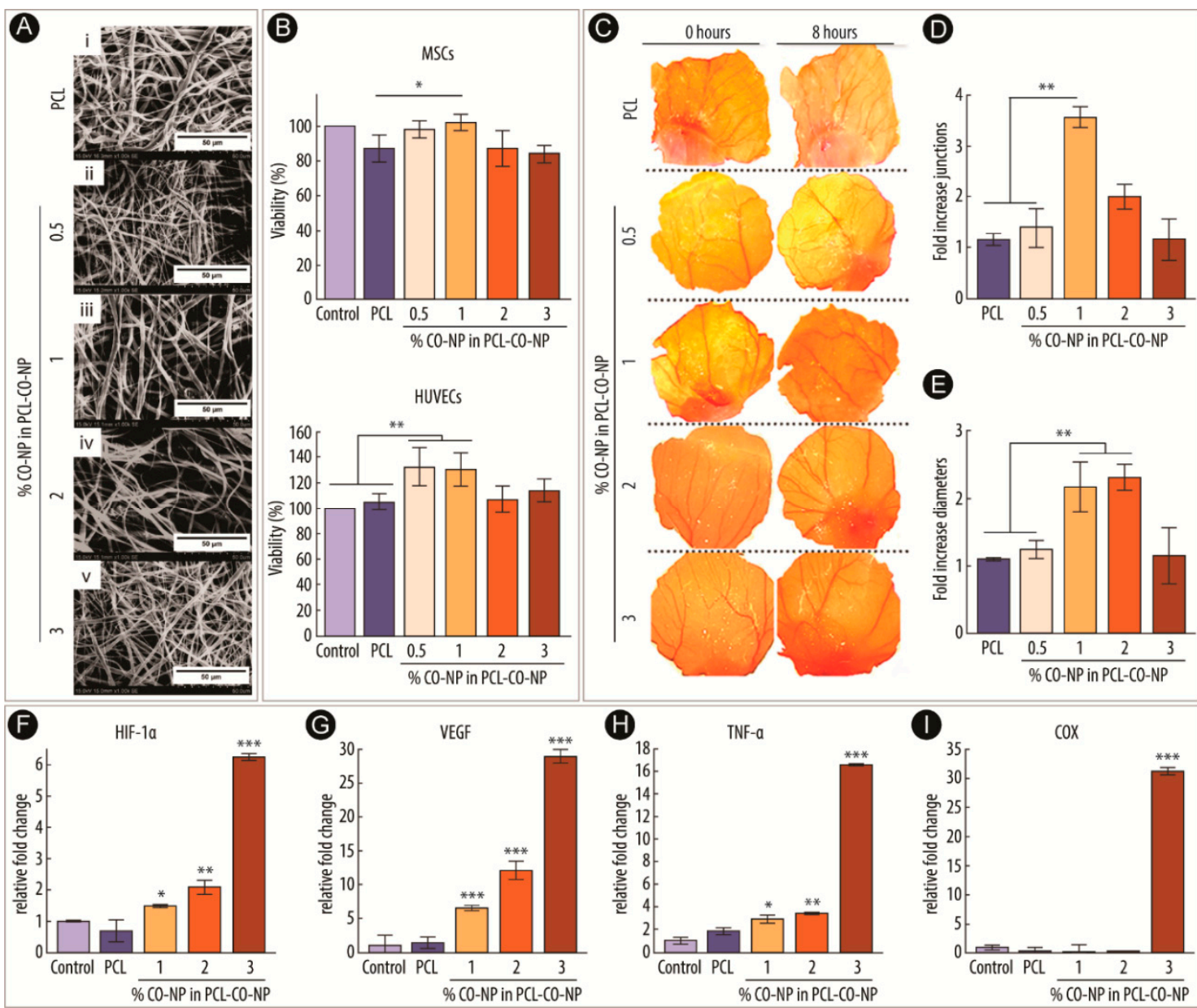

\section{E}
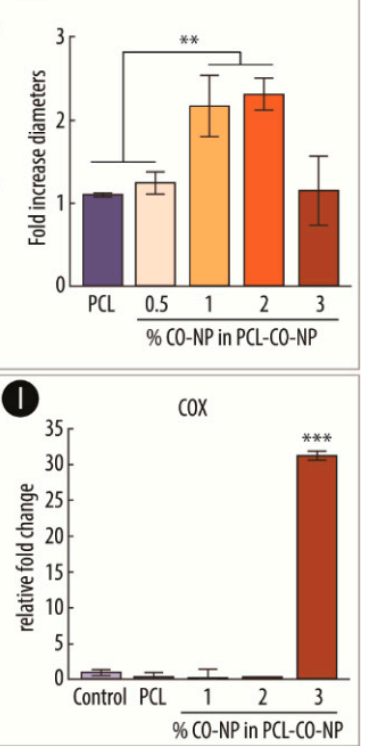

Figure 3. Cerium-oxide nanoparticles (CO-NPs) used for angiogenesis in tissue engineering scaffolds. SEM images of electrospun polycaprolactone (PCL) scaffolds, with different ratios of CO-NPs incorporated $(\%, w / w)(\mathbf{A})$. Cell viability of mesenchymal stem cells (MSCs) and human umbilical vein endothelial cells (HUVECs) on the different scaffolds (B). Angiogenesis assay using the chick chorioallantoic membrane (CAM) model incubated with PCL and PCL-CO-NP scaffolds after 0 and $8 \mathrm{~h}$ (C). Corresponding blood vessel junctions (D) and diameter of blood vessel fold increase (E). Expression of hypoxia-inducing factor $1 \alpha($ HIF-1 $\alpha)($ F), vascular endothelial growth factor (VEGF) (G), tumor necrosis factor $\alpha(\mathrm{TNF}-\alpha)(\mathbf{H})$, and cyclooxygenase (COX) (I) in tissues isolated from implanted scaffolds; ${ }^{*} p<0.05,{ }^{* *} p<0.001,{ }^{* * *} p<0.0001$ vs. control. Reprinted with permission from Reference [86]. Copyright 2018, American Chemical Society.

Alternatively, by taking advantage of both their catalytic and magnetic properties, IO-NPs were also evaluated in the context of therapeutic angiogenesis [70].

The most widely used method for therapeutic angiogenesis involves the direct injection of cell suspensions by injection needles, and an important challenge relates to the rapid cell loss resulting from the leakage of the injection fluid. Additionally, further cell loss occurs due to unstable cell homing and needle-mediated tissue damage [87-89]. IO-NPs were employed to develop a novel strategy for cell implantation by taking advantage of their magnetic properties. As such, as an alternative 
method to cell injection, the Murohara group fabricated cell sheets which were evaluated in vivo for therapeutic angiogenesis [70]. The cell sheets were assembled employing a magnetic force onto MSCs pre-loaded with IO-NPs. MSCs were the cell of choice due to their pro-angiogenic potential as a result of their ability to release of several angiogenic growth factors including VEGF, bFGF, and stromal cell-derived factor- $1 \alpha[90,91]$. The MSCs were incubated with lipid-coated IO-NPs, and multi-layered cell sheets were created, employing a magnet on the reverse side. The ability of the as-prepared cell sheets in promoting angiogenesis was evaluated in mice subjected to unilateral hind limb ischemia. The enhanced angiogenesis for the group implanted with the MSC-sheets was shown by a greater degree of blood perfusion. At the microcirculation level, significantly increased tissue capillary and arteriolar densities for harvested ischemic tissues were observed for the MSC-sheet group. The cell viability of the cells within the MSC-sheets was also assessed. This is an important fact since reported studies of cell transplantation via the direct syringe injection method reported cell viabilities of only $3-5 \%$ at postoperative day seven $[88,89]$. The results revealed a significantly lower number of apoptotic cells in the ischemic muscles of the MSC-sheet group as compared to the MSC-injected group. The authors speculated that the inhibition of cell apoptosis might be a result of the suppression of ROS production via the peroxidase-like activity. The antioxidant properties due to the IO-NPs labeling were also assessed in terms of blood flow recovery of ischemic tissues. The results showed higher capillary and arteriolar densities in ischemic tissues on postoperative day 21 following transplantation with the MSC-sheets. Taken together, the as-prepared MSC-sheets with improved MSC and host cell viability could potentially improve cell therapy for regenerative medicine in ischemic diseases.

In a follow-up study, the Murohara group constructed multi-layered cell sheets employing induced pluripotent stem cell (iPSCs)-derived fetal liver kinase-1 positive $\left(\right.$ Flk-1 $\left.{ }^{+}\right)$cells [92]. Flk-1 ${ }^{+}$cells were the cell line of choice due to their reported ability in promoting angiogenesis in a hind limb ischemia mice model [93]. Similarly to their previous study, the authors constructed multi-layered Flk- $1^{+}$cell-sheets but, in contrast to previous work [70], this time, the Flk-1+ ${ }^{+}$cells were mixed with an extracellular matrix (ECM) precursor embedding system (Figure 4A). A magnet was then placed on the reverse side, and the magnetized Flk- $1^{+}$cells were subsequently assembled into multiple layers following a magnetic force. Figure 4B shows how the obtained sheets had a nearly circular shape with a diameter of $8 \mathrm{~mm}$. The sheet was $\sim 300 \mu \mathrm{m}$ thick, with a "net-like pattern" structure comprising 15-20 cell layers. Next, the Flk- $1^{+}$cell-sheets were implanted in a murine model of hind limb ischemia, and their potential to promote angiogenesis in vivo was evaluated. Similar to their previous study, the antioxidant peroxidase-like activity of the IO-NPs was used to enhance the cell viability of the implanted cells. Via laser Doppler blood flow and capillary density analysis, it was possible to demonstrate the ability of the Flk- $1^{+}$cell-sheets in promoting re-vascularization (Figure 4C-H). Furthermore, the Flk- $1^{+}$cell-sheets enhanced the expression of both VEGF and bFGF in ischemic tissues (Figure 4I,J, respectively).

\subsection{Bone Tissue Engineering}

Surgical operations for the reconstruction of lost or damaged bones involve the use of autografts, allografts, or ceramic and metallic implants. However, such methods have several drawbacks including donor site morbidity, transmission of pathogens, and serious mismatching between the properties of the implanted materials and the native bone [94]. Thus, novel approaches for bone repair resulting from trauma, tumor resection, or skeletal abnormalities are highly sought after.

During the past decades, the field of bone tissue engineering emerged as a powerful alternative. The aim is either to create new tissue in vitro or to promote the regeneration of the tissue in situ by growing cells on scaffolds [95-97]. Thus, biomaterial-based scaffolds are conceived to support the required cell growth, differentiation, and mineralization for tissue regeneration [98-100]. 

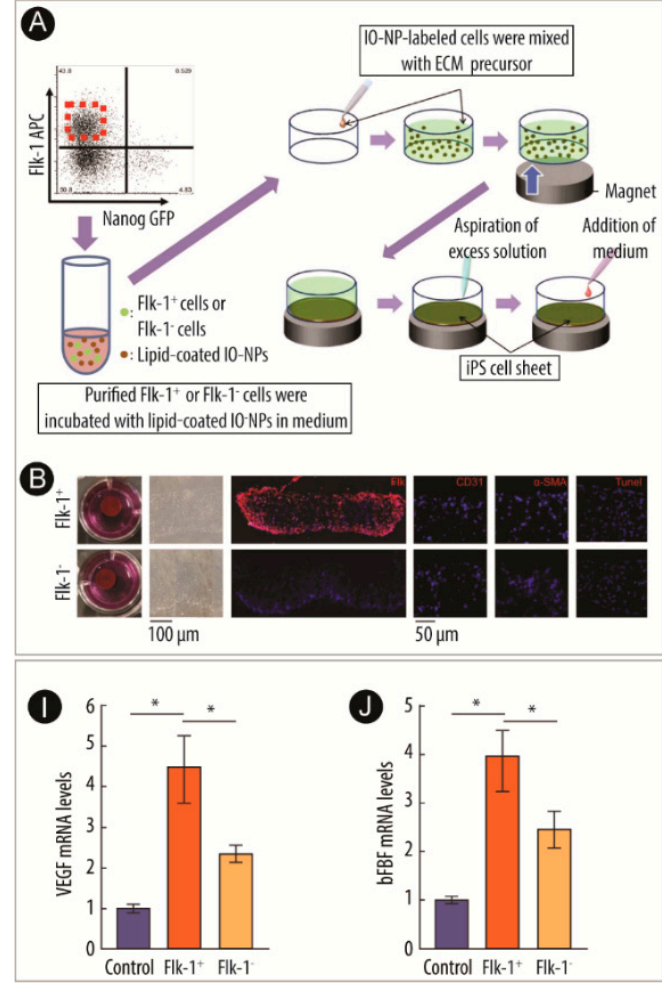

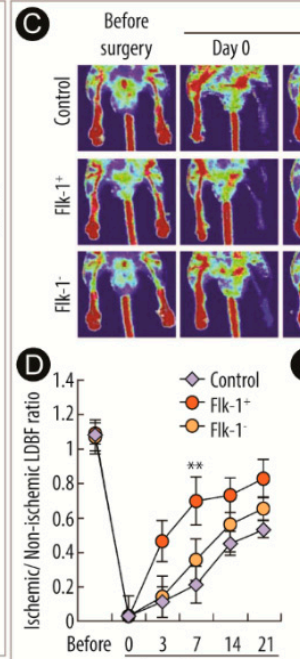

surgery Days after surgery

G

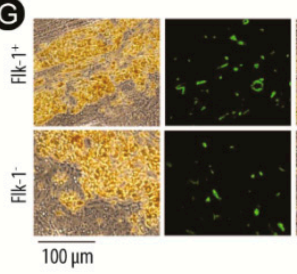

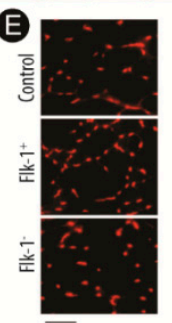

$\overline{50 \mu \mathrm{m}}$

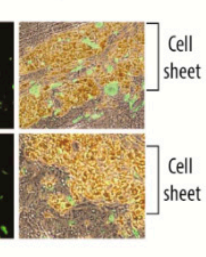

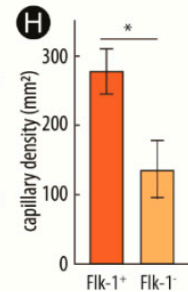

Figure 4. Induced pluripotent stem cell (iPSC) sheet created by employing iron-oxide nanoparticles (IO-NPs) for reparative angiogenesis. Construction of iPSC-derived cell sheet by incubating fetal liver kinase-1 positive or negative (Flk-1 ${ }^{+}$or Flk-1 ${ }^{-}$) cells with lipid-coated IO-NPs, followed by combining with extracellular matrix (ECM) precursor (A). Histological examination of iPSC cell sheets, showing the sheet, bright-field imaging of cell layers, and staining with Flk-1, CD31, $\alpha$ SMA, and TUNEL, respectively $(\mathbf{B})$. Laser Doppler blood flow (LDBF) images after treatment with ECM precursor gel sheet (control), Flk-1+ ${ }^{+}$cell sheet, and Flk-1 ${ }^{-}$cell sheet (C). Quantitative analysis of ischemic/normal LDBF ratio (D); ${ }^{*} p<0.05,{ }^{* *} p<0.001$ vs. control and Flk-1 ${ }^{-}$. Photograph of capillary networks (red $=$CD31) on day 21 (E). Quantitative analysis of capillary density in ischemic tissue (F). Photograph of capillary networks within and around the cell sheet (green = CD31) on day $21(\mathrm{G})$. Quantitative analysis of capillary density (H). VEGF (I) and basic fibroblast growth factor (bFGF) (J) messenger RNA (mRNA) levels in ischemic hindlimb muscles on day seven, normalized to GAPDH mRNA levels. Reprinted with permission from Reference [92]. Copyright 2013, Springer Nature.

As a result of the nanozymes' ability to enhance cell viability and proliferation, naturally, their potential in bone tissue engineering started to be recognized [101]. Reports in that direction mainly focused on assessing the effects of CO-NPs and IO-NPs on cell differentiation following their incorporation within a biomaterials scaffold. A first study was reported by Karakoti and co-workers by exploring the effects of CO-NPs on the osteogenic differentiation of human MSCs (hMSCs) [101]. Bone marrow-derived MSCs (BMSCs) are an interesting cell type for bone regeneration, since they are able to differentiate into osteoprogenitor cells, while also having a central role in angiogenesis, a crucial process for the development of a vascular network to provide the required nutrients to the newly formed bone. To guide and stimulate the growth of bone tissue, CO-NPs were incorporated into bioactive glass scaffolds. Bioactive glass scaffolds were the material of choice due to their interconnected porous network and compressive strength, which is similar to that of cancellous bone [102]. In addition, bioactive glass scaffolds were reported to promote the formation of bone matrix from primary human osteoblasts [103]. Such bone matrix was furthermore able to mineralize in vitro without the need for osteogenic supplements that are usually employed for other bioceramic scaffolds. Karakoti and co-workers fabricated the $70 \mathrm{~S} 30 \mathrm{C}\left(70 \% \mathrm{SiO}_{2}, 30 \% \mathrm{CaO}\right)$ bioactive glass scaffolds via a sol-gel foaming 
process, and the CO-NPs were introduced while the sol was still liquid [101]. This resulted in CO-NP entrapment within the pore walls. The ability of the seeded hMSCs to differentiate toward the osteogenic lineage was evaluated following alkaline phosphatase (ALP) expression after 10 days in culture. ALP is an enzyme produced by MSCs and osteoblasts, involved in the mineralization of bone tissue. During mineralization, hydroxyapatite crystals are formed, which propagate into the ECM where they are deposited between the collagen fibrils [104]. The results showed the highest number of ALP-positive cells for hMSC cultured on CO-NP-containing scaffolds, thus suggesting the highest hMSC differentiation. Importantly, an ALP signal was obtained without the addition of exogenous osteogenic factors (e.g., ascorbic acid, dexamethasone, or $\beta$-glycerophosphate). Next, the deposition of ECM was evaluated by quantifying the amount of produced collagen. Following 10 days of incubation, hMSCs produced significantly higher amounts of collagen when cultured onto CO-NP-containing scaffolds as compared to the bare ones. The authors speculated that such beneficial effects of the CO-NPs on the differentiation of hMSCs could be attributed to the ability of the CO-NPs to act as an oxygen buffer.

In a different study, CO-NP-containing bioactive glass scaffolds were evaluated for their CAT-mimicking activity. It was found that such catalytic activity was dependent on the amount of incorporated CO-NPs [105] and the composition of the bioactive glass scaffold [106], where phosphate-containing scaffolds displayed a lower enzymatic activity. Furthermore, CO-NPs incorporated into bioactive glass fibers resulted in antibacterial properties toward both Gram-negative and Gram-positive bacteria [107]. A meta-analysis of CO-NPs suggested that adsorption onto the microbial cell wall, $\mathrm{Ce}(\mathrm{IV})$ reduction, elevated $\mathrm{pH}$, and oxidative stress rendered the antimicrobial properties of CO-NPs [108]. This would, in turn, improved the success of implanted materials by minimizing infections. Lu and co-workers also used CO-NP-containing bioactive glass scaffolds and, this time, different $\mathrm{Ce} / \mathrm{Ca}$ ratios were evaluated [109]. Employing BMSCs, a positive relationship between the CO-NP content and extracellular calcium deposition could be demonstrated. The authors furthermore showed that the CO-NP-containing scaffolds induced upregulation of the extracellular-signal-regulated kinase (ERK) pathway to promote osteogenic differentiation of the BMSCs. Calvarium skull defects were induced in vivo and implanted with the CO-NP-containing scaffolds $(\mathrm{Ce} / \mathrm{Ca}$ ratio $=1: 3)$ or empty scaffolds. Bone mineral density and bone volume improved significantly when CO-NPs were incorporated into the scaffolds. Tissue staining showed increased osteoblast formation, collagenous deposition, and biomineralization, thus highlighting the positive effect of CO-NPs on the regeneration of new bone tissue.

BMSCs were also used by the Zheng group to assess the osteogenic potential of CO-NPs. However, this time, titanium-based scaffolds were considered [110]. To study the effect of the Ce valence state of the CO-NPs, coatings with high $\mathrm{Ce}(\mathrm{III})$ and high $\mathrm{Ce}(\mathrm{IV})$ content were prepared-CO-A $(67.5 \% \mathrm{Ce}(\mathrm{III}))$ and CO-B (78.8\% Ce(IV)), respectively. Incubation with BMSCs showed increased proliferation, ALP activity, and calcium deposition for the CO-B coating. These data, thus, enhanced the osteogenic potential of CO-NPs with high Ce(IV) content. In a follow-up study, the same group assessed the effect of the Ce valence state on the inflammatory response of RAW264.7 macrophages [110]. In contrast to the bare titanium substrate, coating with CO-NPs resulted in the downregulation of pro-inflammatory cytokines (interleukin (IL)- 6 and TNF- $\alpha$ ) and the upregulation of anti-inflammatory cytokines (IL-1ra and IL-10). Importantly, these effects were more prominent for the CO-B coatings, highlighting the anti-inflammatory properties of $\mathrm{Ce}(\mathrm{IV})$. The Zheng group next conducted a more in-depth investigation of the macrophage response to Ce(IV)-dominant coatings, which resulted in the upregulation of the reparative (M2) macrophage phenotype and the upregulation of anti-inflammatory and osteoinductive molecules by the macrophages [111].

The effect of the Ce valence state was also evaluated by Naganuma and Traversa employing CO-NP-containing poly-L-lactide (PLA) coatings [112]. The authors were able to demonstrate that, while dominant $\mathrm{Ce}(\mathrm{IV})$ coatings promoted cell proliferation, dominant $\mathrm{Ce}(\mathrm{III})$ coatings resulted in a change in cell morphology and a decrease in cell proliferation for the two studied cell lines (MSCs and 
osteoblast-like cells). As such, all in all, the results indicate that higher $\mathrm{Ce}(\mathrm{IV})$ promotes osteogenic activity on MSCs and anti-inflammatory effect on macrophages. The antioxidant properties of CO-NPs in the context of bone tissue engineering were also evaluated by Li and co-workers [113]. BMSCs were seeded onto CO-NP-containing titanium surfaces, followed by exposure to $\mathrm{H}_{2} \mathrm{O}_{2}$. The authors were able to show no increase in ROS levels for the CO-NP-containing substrates, thus highlighting the potential of CO-NPs in reducing oxidative injury. Additionally, CO-NP-containing coatings were able to counteract the inhibition of osteogenic differentiation caused by $\mathrm{H}_{2} \mathrm{O}_{2}$.

One of the main challenges for bone scaffolds following implantation is to achieve sufficient blood supply. Without sufficient blood perfusion or blood vessel distribution, tissue fibrosis and necrosis will lead to failure of the implant. Angiogenesis can be promoted by sprouting blood vessels from the existing vasculature using endothelial cells, or new blood vessels not dependent on the existing vasculature can be formed employing endothelial progenitor cells (EPCs) [114]. This second phenomenon is called vasculogenesis. A first example assessing the potential of CO-NPs to induce the formation of new vessels was conducted by coating acellular cancellous bone by a mixture of PLA and CO-NPs [115]. The coated scaffold was evaluated by seeding a mixture of MSCs and EPCs in a non-contacting co-culture system where MSCs and EPCs were seeded onto the apical and basolateral compartments, respectively (Figure 5A). Increased EPC cell viability (Figure 5B) and expression of differentiation-related genes confirmed that co-culture with CO-NP-containing scaffolds promoted angiogenic differentiation. The results also showed an increase in VEGF expression for MSCs cultured onto the CO-NP-containing scaffolds which would, in turn, result in augmented EPC growth and differentiation. The increase in VEGF expression was furthermore linked to improved HIF-1 $\alpha$ stability, caused by increased intracellular $\mathrm{Ca}^{2+}$ concentrations (as summarized in Figure 5E), which was in agreement with previously reported studies [116-118]. After 28 days of co-culture, tube formation of EPCs was detected, showing a large amount of branching points and tubes. This was also tested in vivo where MSCs were seeded onto CO-NP-containing scaffolds which were then subcutaneously implanted. Higher vascularization was observed for the CO-NP-containing scaffolds as compared to the bare ones (Figure 5C). To evaluate whether vascularization resulted in improved bone tissue formation, the scaffolds were stained at six and 12 weeks following implantation. In contrast to the bare scaffolds, immature bone tissue was formed throughout the CO-NP-containing scaffolds as shown by Masson trichrome staining (Figure 5D). This, together with the in vitro results, indicates that increased penetration of blood vessels as a result of the CO-NPs enhances the formation of new bone tissue within the scaffold.

Together with osteoarthritis, cartilage injuries are a major cause of disability. A major challenge in cartilage engineering is the harsh inflammatory response resulting from injured or arthritic joints, which causes rejection following biomaterial implantation [119-122]. Thus, due to their ability to scavenge ROS and nitrogen species, CO-NPs were also explored to combat inflammation in the context of cartilage engineering [123]. In particular, bovine chondrocytes were cultivated onto a CO-NP-containing agarose scaffold and exposed to IL- $1 \alpha$, which was previously shown to hamper the growth of engineered cartilage and damage the newly formed tissue [124-126]. The results showed no significant decrease in Young's modulus for the CO-NP-containing scaffolds, thus suggesting tissue preservation. Additionally, no decrease in the chondrocyte viability was observed for the treatment groups as shown by the DNA content. However, a decrease in both glycosaminoglycan and collagen content, which are the two main components of the ECM, suggested a limited protective effect for the CO-NP-containing scaffolds.

Motivated by the intrinsic peroxidase-like activity of IO-NPs and the central role of $\mathrm{H}_{2} \mathrm{O}_{2}$ in cell growth, IO-NPs were also investigated in the context of bone tissue engineering.

In a first example, the osteogenic potential of IO-NPs was assessed by embedding them within calcium phosphate cement (CPC) [127]. Cements are an interesting material for bone tissue engineering due to their paste-like application into the bone defects, followed by their ability to harden and mineralize in situ [128]. Dental pulp stem cells (DPSCs) were used in this example since they are 
easier to obtain than BMSCs while having a similar differentiation and gene expressions $[129,130]$. The results showed increased cell spreading and adherence to the CPC for magnetized IO-NP-containing scaffolds [127]. Enhanced ALP, Runt-related transcription factor 2 (RUNX2), and osteocalcin (OCN) gene expression was also observed. By demagnetizing the IO-NPs, it was furthermore concluded that magnetism without an external magnetic field (MF) did not affect the DPSC behavior. In a follow-up study, an MF was applied to the IO-NP-containing CPC scaffold [131] and a nearly four-fold increase in mineral deposition was achieved. Upregulation of ALP, RUNX2, COL1, and OCN, further showed the MF effect on osteogenic differentiation for IO-NP-containing scaffolds.

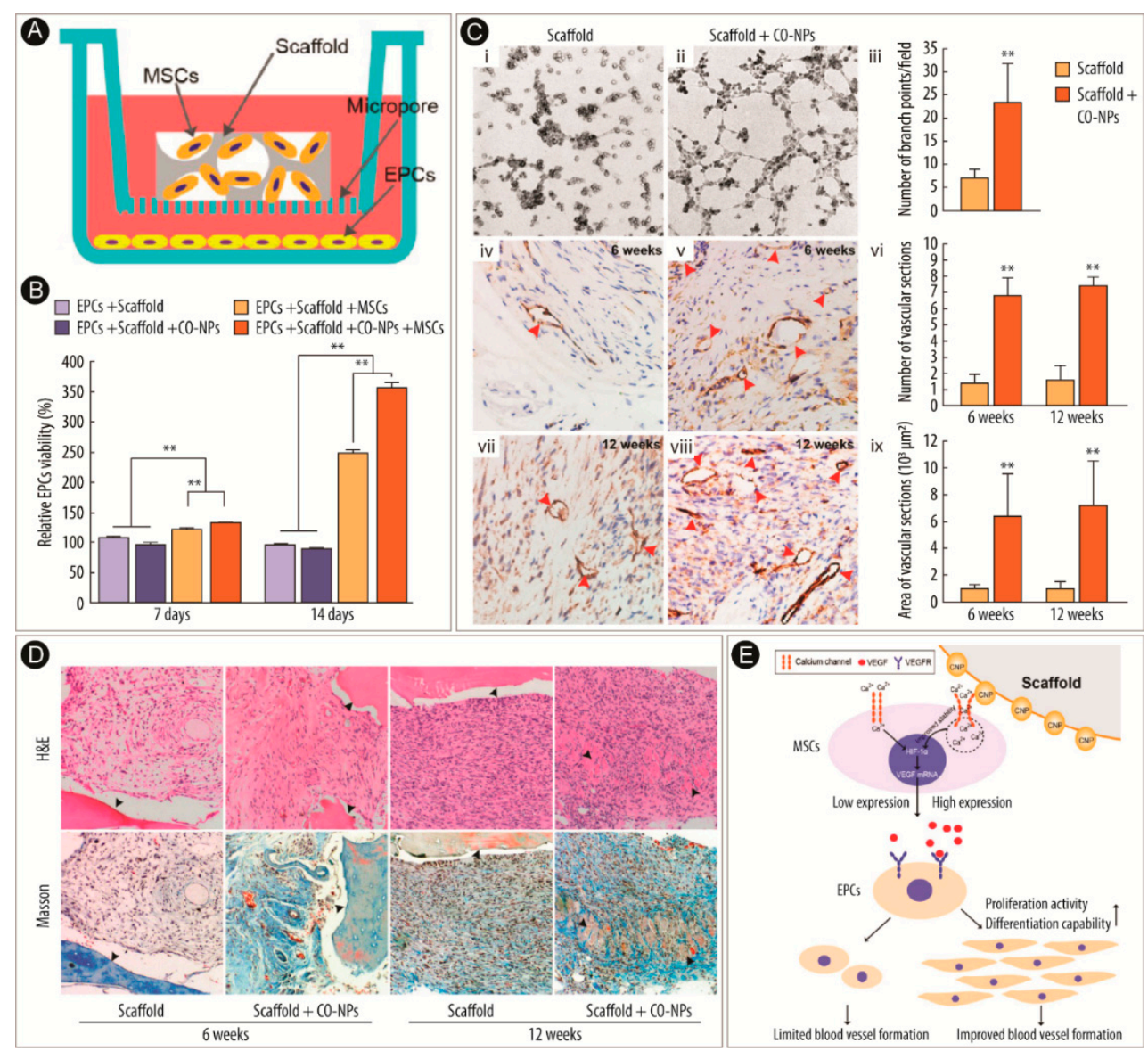

Figure 5. Cerium-oxide nanoparticle (CO-NP)-modified scaffold interface enhances vascularization of bone grafts. Scheme of the non-contacting co-culture used in this study (A). Cell viability of endothelial progenitor cells (EPCs) co-cultured with MSCs on scaffolds \pm CO-NPs at seven and 14 days (B). Tube formation of EPCs co-cultured with MSCs \pm CO-NPs (C): (i,ii), the statistic results of branch points/field (iii); immunohistochemistry staining of scaffolds six weeks (iv,v) and 12 weeks (vii,viii) after implantation; (vi, ix) vascular sections formed inside the scaffolds; ${ }^{* *} p<0.01$. H\&E and Masson trichrome staining of scaffolds six and 12 weeks after implantation (D). Black arrowheads indicate the original scaffold. Schematic of the proposed mechanisms of CO-NPs enhancing the angiogenesis of EPCs (E). CO-NP interaction with MSC membrane could activate calcium channels, thereby increasing intracellular $\mathrm{Ca}^{2+}$ levels. Raised $\mathrm{Ca}^{2+}$ levels improve the HIF- $1 \alpha$ stability, promoting a high expression of VEGF and subsequently activating the EPC proliferation and differentiation capability. Reproduced with permission from Reference [115]. Copyright 2016, American Chemistry Society.

As with CO-NPs, IO-NPs were also incorporated into bioactive glass scaffolds. IO-NP-containing borosilicate glass scaffolds reported enhanced osteogenic differentiation of BMSCs and increased healing capacity of a calvarial defect in a rat model as compared to the bare scaffolds [132]. 
IO-NPs were also incorporated into polymeric scaffolds which were fabricated via electrospinning [133], or via composite fabrication [134] and 3D printing [135,136]. Biocompatible polymers explored so far include PLA [137], poly(lactic-co-glycolic acid) (PCL) [138], poly(urethane) [139], and chitosan [134]. A drawback for polymer-based scaffolds is their low mechanical strength. As such, a promising approach is the incorporation of osteoconductive hydroxyapatite (HA)-NPs within the scaffold. As an example, HA-NPs were incorporated into PLA fibers fabricated via electrospinning [140]. Such a scaffold demonstrated increased cell proliferation and osteogenesis for the pre-osteoblast MC3T3-E1 cell line. These positive effects were further enhanced in the presence of an MF. The authors speculated that the incorporation of IO-NPs resulted in the production of huge amounts of miniature magnetic forces within the scaffold under the external MF, continuously stimulating osteoblast cell proliferation and differentiation. Next, the scaffolds were implanted in a bone defect model in vivo, and the animals were kept in the presence of an MF [141]. The effects of the scaffolds were firstly evaluated by the detection of OCN, which is an ECM protein produced by the osteoblast cells during the formation of new bone (Figure 6A). The results showed the highest $\mathrm{OCN}$ levels for animals treated in the presence of the MF for the three studied time points (i.e., 10, 20, and 30 days). Figure 6B shows clearer and denser collagen fibers upon application of the MF. Evaluation by micro-computed tomography (micro-CT) and hematoxylin and eosin (H\&E) tissue staining furthermore showed a faster remodeling process under the $\mathrm{MF}$, which was attributed to the magnetic response of the IO-NPs incorporated in the scaffold (Figure 6C,D). In a follow-up study, the inflammatory response of IO-NP-containing scaffolds was evaluated [142]. The macrophages showed an increased angiogenic capacity, as well as enhanced recruitment of pre-osteoblasts, indicating improved bone regenerating potential when exposed to the IO-NP-containing scaffold in a MF.
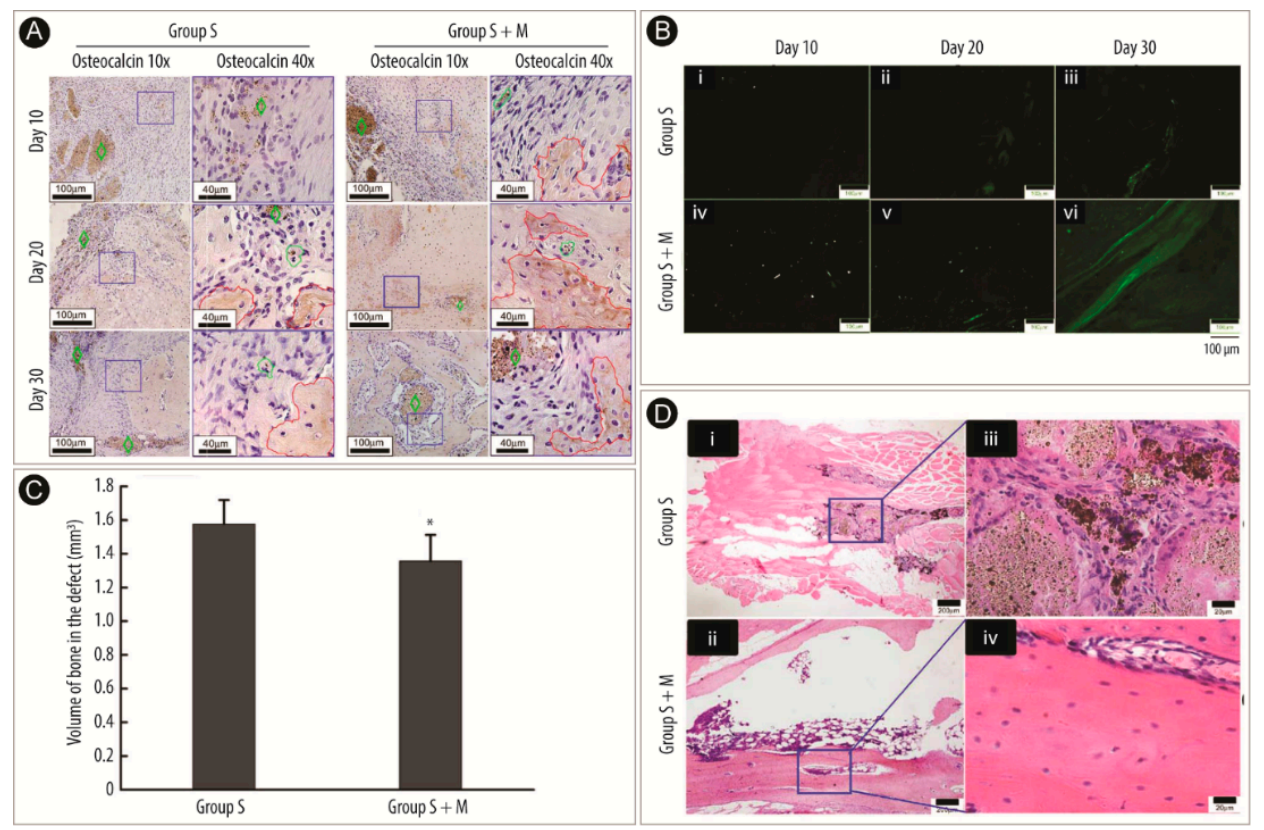

Figure 6. Superparamagnetic responsive scaffolds under a magnetic field enhance osteogenesis for bone repair in vivo. Osteocalcin (OCN) expression induced by the iron-oxide nanoparticle (IO-NP)-containing scaffolds (S) \pm magnetic field (M) after 10, 20, and 30 days after implantation (A). Red outlined area $=$ positive cells, green rhombus = scaffold. Collagen deposition in the scaffolds (B). Stained with Sirius red. Amount of new bone formed in the defects after 110 days, obtained from micro-computed tomography (micro-CT) $(\mathrm{C}) ;{ }^{*} p<0.1$. Histological observation of the bone defects after 110 days of implantation (D): (iii,iv) magnifications of the areas in (i,ii), respectively. In (iii), a small amount of scaffold remains can be seen. In (iv), a homogeneous and well-organized bone formation in the defect is observed. Reprinted with permission from Reference [141]. Copyright 2013, Springer Nature. 
Components of the ECM such as collagen or gelatin were also employed to construct IO-NP-containing scaffolds $[143,144]$. To improve the mechanical strength of collagen scaffolds, a common approach is to apply plastic compression $[145,146]$. Their potential was evaluated both in vitro [144] and in vivo [143], and results showed increased osteogenic differentiation of osteosarcoma cells and enhanced bone formation within the incisor sockets of a rat model. Importantly, the beneficial effects were enhanced in the presence of an MF. Importantly, due to the magnetic properties of the IO-NPs, they could be used as negative contrast agents in MRI. This made it possible to track the in vivo bone regeneration.

Metallic implants were also investigated. In this context, titanium surfaces were coated with IO-NPs, making use of the self-polymerization of dopamine into polydopamine [147]. Improved cell attachment, proliferation, and cell-cell interaction of BMSCs in vitro was observed for the IO-NP-coated surfaces. ALP, OCN, and RUNX2 messenger RNA (mRNA) levels were furthermore significantly increased for the IO-NP coating, thus indicating enhanced osteogenic differentiation. IO-NPs were also deposited onto titanium surfaces via co-deposition with mineralized collagen [148]. In vitro experiments showed that, when the IO-NPs were located in the outer layer of the coating (O-IO-NP), the highest ALP activity was observed. Compared to the bare collagen coating, the IO-NPs resulted in improved cell adhesion. Furthermore, the presence of an MF resulted in increased cell spreading, matrix mineralization, and osteogenic-related gene expression. Enhanced internalization of the IO-NPs by pre-osteoblasts was observed for the O-IO-NP coatings as compared to the IO-NPs located in the inner layer or when homogeneously distributed throughout the coating. These results indicated that IO-NP internalization by the cells could, to some extent, induce osteogenic differentiation in the presence of the MF. This is not surprising since the Gu group previously demonstrated how the internalization of IO-NPs by BMSCs resulted in the upregulation of osteogenic markers [149]. Furthermore, such an upregulation by the IO-NPs took place in a dose-dependent manner.

Lastly, the effect of the IO-NP arrangement on the osteogenic differentiation of MSCs was evaluated [150]. To do so, MFs were employed to fabricate IO-NP-containing substrates with the IO-NPs distributed in a random or striped-like fashion. Additionally, MFs with varying strengths were evaluated. It was shown that the striped-like arrangement was able to enhance both cell proliferation and differentiation. Furthermore, the strength of the MF employed to arrange the IO-NPs had a positive effect on the proliferation and differentiation of MSCs. It was speculated that, as a result of the small size of IO-NPs, the coupling energy between the IO-NPs would then generate highly local micro-fields able to significantly affect close-contacted objects such as the cultured cells.

\subsection{Wound Healing}

Successful wound healing requires an orchestrated cellular response of fibroblasts, keratinocytes, and vascular endothelial cells. While the migration and proliferation of fibroblasts and keratinocytes result in the restoration of the ECM, the growth of vascular endothelial cells promotes the formation of the new vessels required to supply nutrients to the skin cells [151].

Impaired wound healing, which occurs when the ability for skin restoration of one of the three cell types is compromised, can result in various detrimental health outcomes [152]. Two important factors that can favor or hamper the wound-healing process are the ROS and oxygen levels $[101,112,123,153,154]$. While high ROS concentrations impede the course of healing, a good oxygen inflow is beneficial for the process. As such, both CO-NP and IO-NP nanozymes, due to their ability for ROS depletion and $\mathrm{H}_{2} \mathrm{O}_{2}$ reduction into oxygen, respectively, were explored for wound-healing applications.

In a first study, CO-NPs were evaluated in a cutaneous wound-healing murine model [154]. Since cells within and surrounding wounds suffer from high levels of ROS [155], Chigurupati and co-workers hypothesized that CO-NPs, due to their ability to scavenge ROS and nitric-oxide radicals [156], would facilitate the proliferation of the relevant cells, which would, in turn, accelerate the wound-healing process. The authors evaluated the ability of endothelial cells for tube formation in the presence of IO-NPs [154]. To allow for tube formation, endothelial cells were grown in a 3D Matrigel matrix, and 
the results, as assessed by optical microscopy, indicated a three-fold increase in tube formation for cells treated with CO-NPs. Next, the CO-NPs were evaluated in an in vivo mouse model of skin wound healing. The CO-NPs were applied daily to the wounds via topical administration, and the size of the wound was assessed at different time points. The results showed a marked decrease in wound size for mice treated with the CO-NPs as compared to the controls. Further experiments to understand the mechanism revealed that CO-NPs were able to mitigate the both accumulation of a lipid peroxidation product and nitrotyrosine-modified proteins in the wound, thus indicating an antioxidant mechanism of action of the CO-NPs.

Other examples of the topical administration of CO-NPs to enhance wound healing involve the use of chitosan-coated CO-NPs applied onto an open wound rat model [157]. While the chitosan coating was used to enhance the biocompatibility of the CO-NPs, it also resulted in enhancing the wound healing starting from day eight following topical administration. Additionally, the coated CO-NPs were able to heal the wound significantly faster as compared to rhEGF, which is a clinically used wound-healing agent [158].

CO-NPs were also evaluated in the context of diabetic wound healing, since complications due to diabetes represent one of the most challenging medical issues of the 21st century [159]. Within this study, the CO-NPs were conjugated to microRNA with the goal to enhance the inflammatory response [159]. MiR-146a was chosen due to its reported ability to target adapter molecules of the NF- $\mathrm{kB}$ pathway, resulting in increased IL-6 and IL-8 gene expression [160-162]. The authors could show that CO-NP or miR146a treatment alone did not have an effect on the healing rate compared to the saline control in both mouse and pig diabetic wound-healing models. However, when using the conjugated miR164a CO-NPs, the results were different. The healing rate improved significantly, with increased strength and elasticity in the murine model, and decreased inflammatory and increased angiogenesis in the porcine model. Also in the context of diabetes, a first case study of topical administration CO-NPs in diabetic foot ulcers was reported [163]. While initial treatment with orally administered antibacterial Trikacide drug together with a hypertonic solution dressing on the wound did not heal the ulcers, following treatment with a CO-NP-containing gel had a different outcome. Two ulcers were treated and healed successfully, suggesting therapeutic potential for CO-NPs in the topical treatment of diabetic foot ulcers.

Electrospun films for wound dressings incorporating CO-NPs were also evaluated. PCL-gelatin blends are one of the biomaterials investigated for skin tissue engineering, due to their ECM-mimicking properties, biodegradability, and biocompatibility [164]. Rather and co-workers incorporated $\sim 42$-nm-sized CO-NPs (25\% v/v $30 \mathrm{mM}$ solution) into the electrospun fibers [165]. In vitro assays showed an increase in the cell proliferation rate of fibroblasts for the CO-NP-containing fibers as compared to the bare ones. This was correlated to the ROS-scavenging properties by quantifying intracellular ROS levels. CO-NPs were also incorporated into PCL-gelatin fibers $(<25 \mathrm{~nm}$ CO-NPs, $1.5 \% w / w)$ by Naseri-Nosar and co-workers [166]. A full-thickness wound model in male Wistar rats showed almost complete healing for wounds treated with the CO-NP-containing fibers after two weeks of treatment. In contrast, the sterile gauze control wounds were still fresh.

A different application for CO-NPs within wound healing is as tissue adhesives for wound closure. The efficient restoration of the tissue while also minimizing the aesthetic impact following an injury still prevails as a great challenge. While multiple treatment options including sutures, staples, and tissue adhesives are widely available, regenerative healing of the injured tissue rather than fibrotic healing still remains elusive $[167,168]$. To overcome the limitations of current passive healing processes, focus was brought to the microenvironmental processes of the wound site, which include increased ROS production $[152,169]$. Therefore, due to their antioxidant properties, CO-NPs were also used in this context. In particular, mesoporous silica nanoparticles (MSN) coated with CO-NPs (MSN-CO-NPs) were evaluated as novel tissue adhesives (Figure 7A) [170]. Following assessment of their catalytic properties (Figure 7B,C), the MSN-CO-NPs were applied onto 2-cm cutaneous incisions in mice. Within eight days, the wound area was almost repaired and furthermore displayed a smooth appearance 
(Figure 7D,F). The MSN-CO-NP-treated group also yielded higher native collagen deposition and fiber alignment, as well as a thin epidermal thickness, implying limited scar formation (Figure 7E).

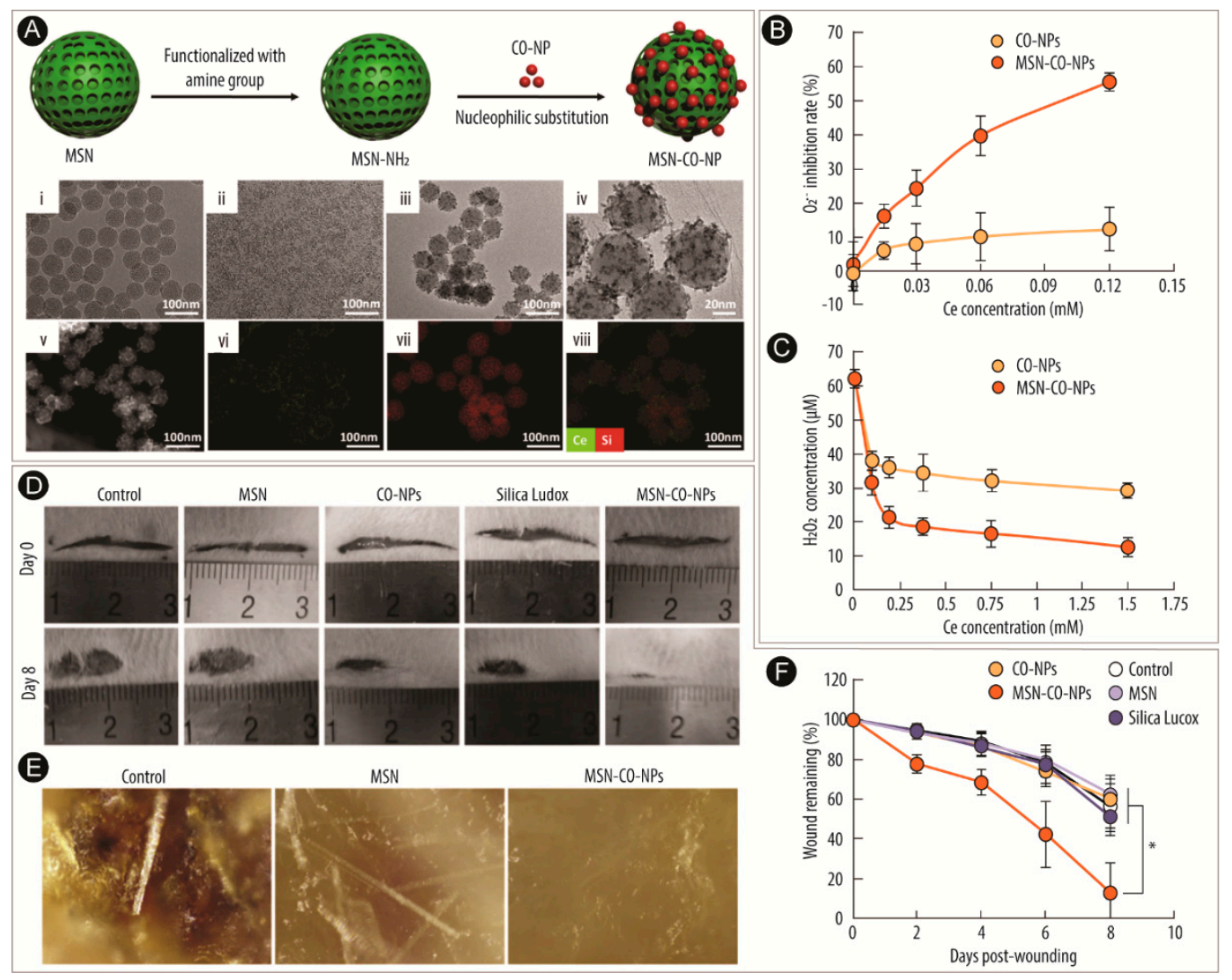

Figure 7. Cerium-oxide nanoparticle (CO-NP)-decorated mesoporous silica nanoparticles (MSNs) for reactive oxygen species (ROS) scavenging in regenerative wound healing. Fabrication process of the MSN-CO-NPs (A), with TEM images of MSN (i), CO-NPs (ii), and MSN-CO-CPs (iii), high-resolution TEM images of MSN-CP-NPs (iv), scanning TEM (STEM) image of MSN-CO-NPs (v), and energy-dispersive $\mathrm{X}$-ray spectroscopy (EDX) element mapping of Ce (green, vi), Si (red, vii), and their overlay (viii) in MSN-CO-NPs. ROS scavenging of $\mathrm{O}_{2}{ }^{--}$(B) and hydrogen peroxide $\left(\mathrm{H}_{2} \mathrm{O}_{2}\right)$ (C) at different concentrations. Images of wound repair during an eight-day in vivo experiment (D). Microstructure of wound surface 22 days post-wounding (E). Quantification of wound repair kinetics as a percentage of initial wound length $(\mathbf{F}){ }^{*} p<0.05$. Reprinted with permission from Reference [170]. Copyright 2017, Elsevier Ltd.

Due to the detrimental and beneficial effects of $\mathrm{H}_{2} \mathrm{O}_{2}$ [171] and oxygen [172] for the wound-healing process, IO-NPs able to catalyze $\mathrm{H}_{2} \mathrm{O}_{2}$ were also explored in wound-healing applications [173]. Incorporation of IO-NPs into three-dimensional (3D) cellular spheroids was shown to stimulate the ECM production $[174,175]$. Additionally, by varying the IO-NP concentration and characteristics, it was also possible to influence its composition. While modulation of the IO-NP concentration had an effect on the production of both collagen IV and elastin, magnetic IO-NPs (magnetoferritin) increased the production of all the proteins constituting the ECM.

Hu and co-workers used IO-NPs in wound dressings made of poly(vinyl alcohol) (PVA) membranes fabricated via electrospinning [173]. A polymeric PVA mesh was chosen as the scaffold due to the high surface-to-volume ratio and porosity, which allow for high water absorption and strong oxygen permeation [176]. Spindle-shaped IO-NPs were prepared (Figure 8A) and integrated within the scaffold fibers by mixing them with a PVA solution, followed by electrospinning (Figure 8B). Figure 8C shows a TEM image of the as-prepared fibers with homogeneously integrated IO-NPs at different 
concentrations. The results, as shown by a colorimetric assay and an oxygen-sensitive electrode (Figure 8D), demonstrate catalytic activity for the IO-NP-containing PVA fibers at all the studied concentrations. The influence of the IO-NPs on the scaffolds was investigated in terms of fibroblast proliferation in the presence of $\mathrm{H}_{2} \mathrm{O}_{2}$ at detrimental concentrations. The catalytic scaffolds supplied a better environment for cell proliferation as shown by more than $90 \%$ cell viability following overnight incubation with the $\mathrm{H}_{2} \mathrm{O}_{2}$-exposed nanofibrous dressings containing IO-NPs (Figure 8E). Importantly, complete apoptosis was observed for cells incubated with bare scaffolds. Thus, due to their ability to diminish $\mathrm{H}_{2} \mathrm{O}_{2}$ concentrations to nontoxic levels, the IO-NP-PVA membranes show potential for wound-healing dressings.
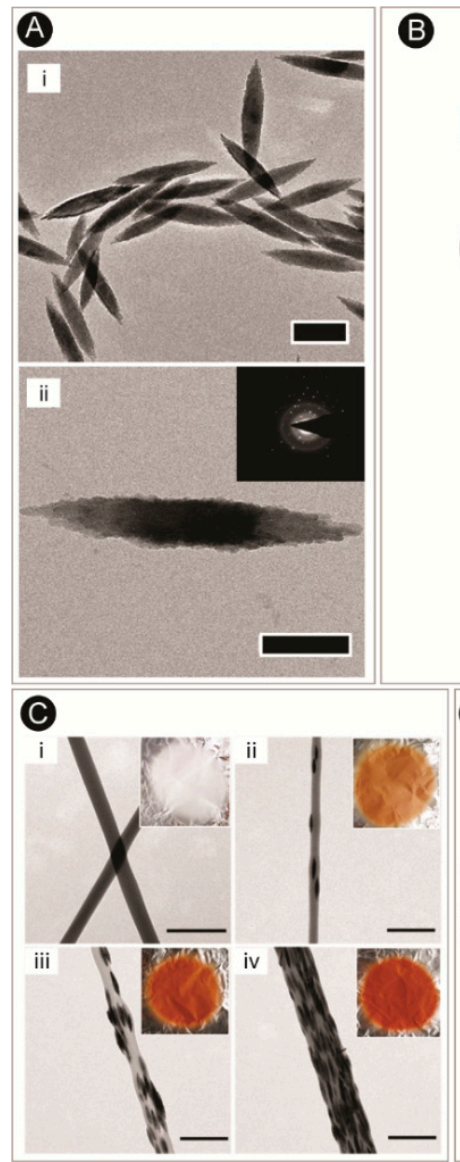

B

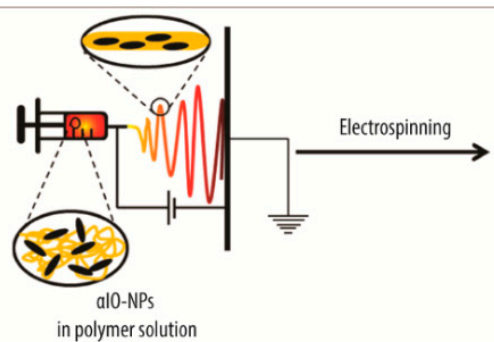

in polymer solution
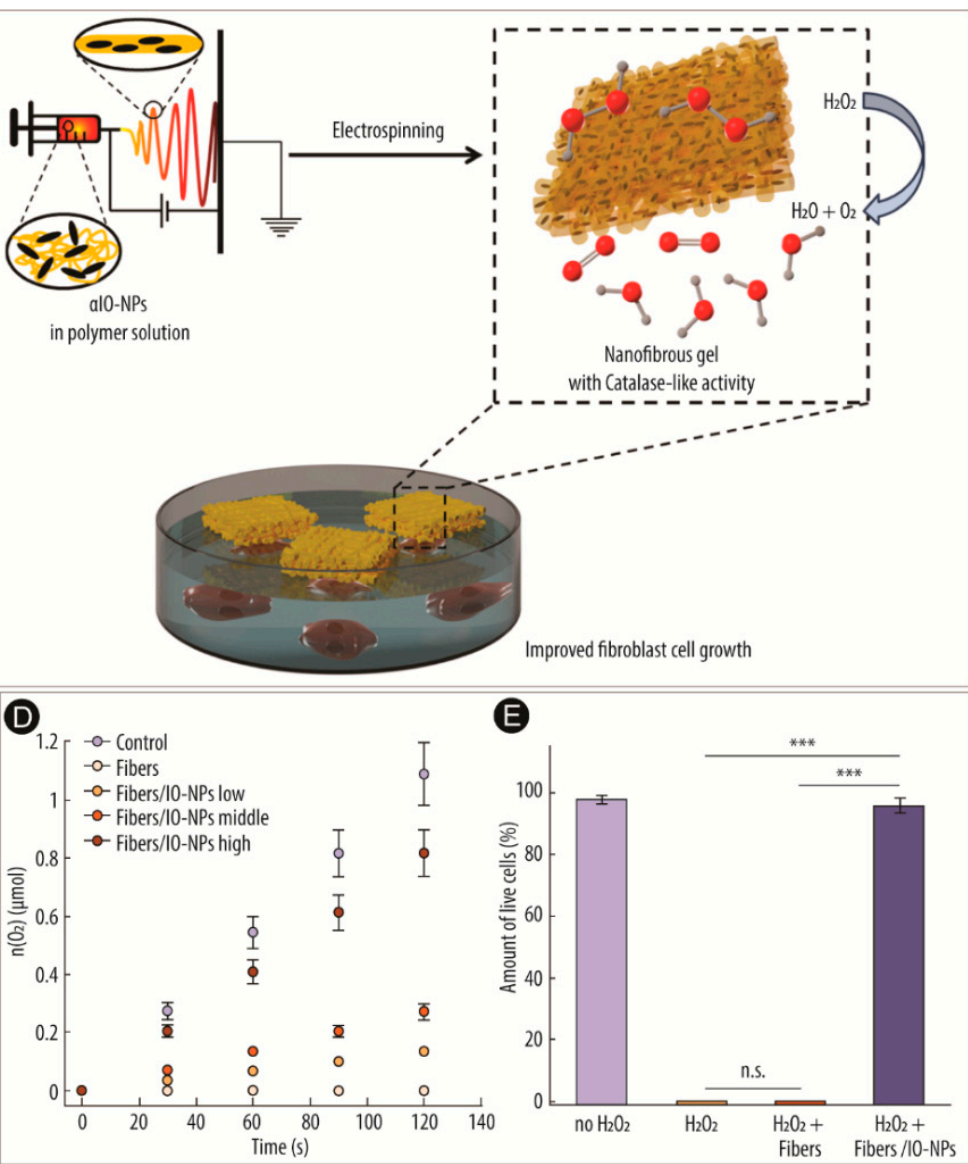

Figure 8. Fibrous dressing containing hematite nanoparticles ( $\alpha \mathrm{IO}-\mathrm{NPs})$ with catalase-like activity to promote wound healing. TEM images of spindle-shaped $\alpha \mathrm{IO}-\mathrm{NPs}$ (A). Scale bar for (i): $200 \mathrm{~nm}$, for (ii): $100 \mathrm{~nm}$. Schematic illustration of the fabrication process of $\alpha \mathrm{IO}-\mathrm{NPs}$ containing nanofibrous dressings (B). Together with poly(vinyl alcohol) (PVA), the $\alpha$ IO-NPs are electrospun to obtain the dressing, which, due to its catalase-like activity, improves fibroblast cell growth. TEM imaging of electrospun PVA mats containing $0 \%$ (i), $19 \%$ (ii), $58 \%$ (iii), or $71 \%$ (iv) $\alpha$ IO-NPs (C). Scale bar: $1 \mu \mathrm{m}$. Catalase-like activity was analyzed by measuring the amount of elemental oxygen $\left(\mathrm{n}\left(\mathrm{O}_{2}\right)\right)$ being produced over time (D). Cell viability after exposure to $\mathrm{H}_{2} \mathrm{O}_{2}$-incubated nanofibrous dressings $(\mathbf{E})$; ${ }^{* * *} p<0.001$. Reprinted with permission from Reference [173]. Copyright 2017, American Chemical Society.

The $\mathrm{Xu}$ and $\mathrm{Gu}$ groups used PLA as a polymer in electrosprayed scaffolds [177]. DMSA-modified IO-NPs were incorporated into the fibers to obtain $7.5 \%(w / w)$ loading. Fibroblasts were added, after which a magnetic field was applied. MF intensities of 0,5 , and $10 \mathrm{mT}$ were employed during the in vitro studies (MF0-, MF5-, and MF10-groups, respectively). Evaluation of the expression of pro-angiogenic cytokines VEGF, bFGF, and TGF- $\beta 1$ indicated enhanced angiogenesis upon applying an MF. Additionally, the authors also assessed the potential of the conditioned medium of the fibroblasts 
grown on the scaffolds to induce angiogenesis, wound healing, and an inflammatory response. This is of interest since it could avoid scaffold-induced fibrosis. The results showed how the conditioned media increased the migration of naïve fibroblasts, while an overall reduced inflammatory response could be observed. When adding the conditioned media to endothelial cells, more vessel-like tubes were formed for the MF-exposed group (1.7-fold for MF5, and 1.6-fold for MF10 compared to MF0). This indicates that the MF promotes the capacity to form endothelial tubes.

\section{Conclusions}

This review started with a brief introduction to the field of enzyme mimics based on nanoparticulate materials, followed by highlighting the progress made in regenerative medicine and tissue engineering applications.

While the aforementioned examples showed the progress on the development of nanozymes, there are still important challenges that need to be addressed for nanozymes to become a reality in the clinic.

Despite the overwhelming and increasing number of publications on nanozymes, mainly cerium- and iron-oxide nanoparticles were explored so far. As such, there is substantial room for future developments by exploring other well-developed nanomaterials with enzyme-like properties. The current applications of nanozymes in regenerative medicine and tissue engineering mainly rely on the antioxidant abilities of nanozymes with a main emphasis on ROS removal. However, since natural enzymes are able to catalyze six different types of reactions, exploring new catalytic activities different from redox reactions can result in novel and unexpected therapeutic applications. Additionally, it is noted that, in addition to magnetism, other functions including optical, thermal, or fluorescence properties arising from materials at the nanoscale should also be explored. This could open up exciting and important new research directions. Last but not least, for such multifunctional materials, there is a complex interplay between catalytic activity, therapeutic efficacy, and biocompatibility. All of them are critical factors when evaluating these materials. Additional hurdles arise when nanozymes are expected to function within our body. For example, nanozymes display distinct enzymatic properties and kinetics depending on the microenvironment (i.e., $\mathrm{pH}$, temperature, or substrate availability). Additionally, the biological milieu (e.g., body fluids) also have an influence on their surface chemistry, which also influences their catalytic activity. Another challenge lies in reaching the desired site of action following intravenous, topical, or implant-mediated administration. Of utmost importance is also to achieve a high biocompatibility. While some of the discussed examples were evaluated both in vitro and in vivo, only one was assessed in a clinical context [163]. While important progress was made for Food and Drug Administration (FDA)-approved tissue engineering materials [178,179], multifunctional or composite products incorporating several materials (nanozymes and polymers), as well as cells, require more extensive preclinical characterization.

For the reviewed IO-NPs and CO-NPs, it is noted that there is a vast variation in shape, size, and surface coatings across the different publications, which would result in different properties including biocompatibility $[180,181]$. While, following intravenous administration, both CO-NPs and IO-NPs can be found mainly in the spleen and liver [182-184], CO-NPs are then excreted through the feces [182], while the iron is eliminated via the metabolic iron pathway [185]. While iron is thought to be biocompatible, it should also be noted that leaked iron ions can cause geno- and cytotoxicity $[185,186]$. Therefore, normalized in vivo assays and meta-analyses could provide important information regarding their safety following administration into our bodies.

Thus, while there is still a long way to go before nanozymes can be implemented in a clinical setting, collaborative efforts from various disciplines including materials science and bioengineering, as well as computational studies, should accelerate the progress of this exciting field.

Author Contributions: Conceptualization, L.H.-R.; validation, L.H.-R. and M.M.T.J.; writing—original draft preparation, L.H.-R. and M.M.T.J.; writing—review and editing, L.H.-R. and M.M.T.J.; visualization, M.M.T.J.; supervision, L.H.-R.; funding acquisition, L.H.-R. 
Funding: This work was supported by the Danish Council for Independent Research (Grant No. 6111-00298B) and the Lundbeck Foundation, Denmark (Grant No. R163-2013-15402).

Conflicts of Interest: The authors declare no conflicts of interest.

\section{References}

1. Wu, J.; Wang, X.; Wang, Q.; Lou, Z.; Li, S.; Zhu, Y.; Qin, L.; Wei, H. Nanomaterials with enzyme-like characteristics (nanozymes): Next-generation artificial enzymes (II). Chem. Soc. Rev. 2019, 48, 1004-1076. [CrossRef] [PubMed]

2. Murakami, Y.; Kikuchi, J.; Hisaeda, Y.; Hayashida, O. Artificial enzymes. Chem. Rev. 1996, 96, 721-758. [CrossRef] [PubMed]

3. Ragg, R.; Tahir, M.N.; Tremel, W. Solids go bio: Inorganic nanoparticles as enzyme mimics. Eur. J. Inorg. Chem. 2016, 2016, 1906-1915. [CrossRef]

4. Korschelt, K.; Tahir, M.N.; Tremel, W. A step into the future: Applications of nanoparticle enzyme mimics. Chem. Eur. J. 2018, 24, 9703-9713. [CrossRef] [PubMed]

5. Turrens, J.F.; Crapo, J.D.; Freeman, B.A. Protection against oxygen toxicity by intravenous injection of liposome-entrapped catalase and superoxide dismutase. J. Clin. Investig. 1984, 73, 87-95. [CrossRef] [PubMed]

6. Arami, H.; Khandhar, A.; Liggitt, D.; Krishnan, K.M. In vivo delivery, pharmacokinetics, biodistribution and toxicity of iron oxide nanoparticles. Chem. Soc. Rev. 2015, 44, 8576-8607. [CrossRef] [PubMed]

7. Walkey, C.; Das, S.; Seal, S.; Erlichman, J.; Heckman, K.; Ghibelli, L.; Traversa, E.; McGinnis, J.F.; Self, W.T. Catalytic properties and biomedical applications of cerium oxide nanoparticles. Environ. Sci. Nano 2015, 2, 33-53. [CrossRef] [PubMed]

8. Grunwald, P. Biocatalysis, 2nd ed.; World Scientific: Hackensack, NJ, USA, 2017; ISBN 978-1-78326-907-5.

9. Chen, Z.; Ji, H.; Liu, C.; Bing, W.; Wang, Z.; Qu, X. A multinuclear metal complex based DNase-mimetic artificial enzyme: Matrix cleavage for combating bacterial biofilms. Angew. Chem. Int. Ed. 2016, 55, 10732-10736. [CrossRef]

10. Kirkorian, K.; Ellis, A.; Twyman, L.J. Catalytic hyperbranched polymers as enzyme mimics; Exploiting the principles of encapsulation and supramolecular chemistry. Chem. Soc. Rev. 2012, 41, 6138-6159. [CrossRef]

11. Klotz, I.M. Synthetic polymers with enzyme-like activities. Ann. N. Y. Acad. Sci. 1984, 434, 302-320. [CrossRef]

12. Kofoed, J.; Reymond, J.L. Dendrimers as artificial enzymes. Curr. Opin. Chem. Biol. 2005, 9, 656-664. [CrossRef] [PubMed]

13. Wulff, G. Enzyme-like catalysis by molecularly imprinted polymers. Chem. Rev. 2002, 102, 1-28. [CrossRef] [PubMed]

14. Pollack, S.J.; Jacobs, J.W.; Schultz, P.G. Selective chemical catalysis by an antibody. Science 1986, 234, 1570-1573. [CrossRef] [PubMed]

15. Singh, S. Nanomaterials exhibiting enzyme-like properties (Nanozymes): Current advances and future perspectives. Front. Chem. 2019, 7, 46. [CrossRef] [PubMed]

16. Wu, J.; Li, S.; Wei, H. Integrated nanozymes: Facile preparation and biomedical applications. Chem. Commun. 2018, 54, 6520-6530. [CrossRef] [PubMed]

17. Cormode, D.P.; Gao, L.; Koo, H. Emerging biomedical applications of enzyme-like catalytic nanomaterials. Trends Biotechnol. 2018, 36, 15-29. [CrossRef]

18. Golchin, J.; Golchin, K.; Alidadian, N.; Ghaderi, S.; Eslamkhah, S.; Eslamkhah, M.; Akbarzadeh, A. Nanozyme applications in biology and medicine: An overview. Artif. Cells Nanomed. Biotechnol. 2017, 45, 1069-1076. [CrossRef]

19. Das, M.; Patil, S.; Bhargava, N.; Kang, J.-F.; Riedel, L.M.; Seal, S.; Hickman, J.J. Auto-catalytic ceria nanoparticles offer neuroprotection to adult rat spinal cord neurons. Biomaterials 2007, 28, 1918-1925. [CrossRef]

20. Niu, J.; Azfer, A.; Rogers, L.M.; Wang, X.; Kolattukudy, P.E. Cardioprotective effects of cerium oxide nanoparticles in a transgenic murine model of cardiomyopathy. Cardiovasc. Res. 2007, 73, 549-559. [CrossRef]

21. Celardo, I.; Pedersen, J.Z.; Traversa, E.; Ghibelli, L. Pharmacological potential of cerium oxide nanoparticles. Nanoscale 2011, 3, 1411-1420. [CrossRef] 
22. Wang, X.; Guo, W.; Hu, Y.; Wu, J.; Wei, H. Nanozymes: Next Wave of Artificial Enzymes, 1st ed.; Springer: Berlin/Heidelberg, Germany, 2016; ISBN 978-3-662-53068-9.

23. Wang, X.; Hu, Y.; Wei, H. Nanozymes in bionanotechnology: From sensing to therapeutics and beyond. Inorg. Chem. Front. 2016, 3, 41-60. [CrossRef]

24. Mailloux, R.J. Teaching the fundamentals of electron transfer reactions in mitochondria and the production and detection of reactive oxygen species. Redox Biol. 2015, 4, 381-398. [CrossRef] [PubMed]

25. Guo, W.; Zhang, M.; Lou, Z.; Zhou, M.; Wang, P.; Wei, H. Engineering nanoceria for enhanced peroxidase mimics: A solid solution strategy. Chem CatChem 2019, 11, 737-743. [CrossRef]

26. Pirmohamed, T.; Dowding, J.M.; Singh, S.; Wasserman, B.; Heckert, E.; Karakoti, A.S.; King, J.E.S.; Seal, S.; Self, W.T. Nanoceria exhibit redox state-dependent catalase mimetic activity. Chem. Commun. 2010, 46, 2736-2738. [CrossRef] [PubMed]

27. Korsvik, C.; Patil, S.; Seal, S.; Self, W.T. Superoxide dismutase mimetic properties exhibited by vacancy engineered ceria nanoparticles. Chem. Commun. 2007, 1056-1058. [CrossRef] [PubMed]

28. Lu, A.-H.; Salabas, E.L.; Schüth, F. Magnetic nanoparticles: Synthesis, protection, functionalization, and application. Angew. Chem. Int. Ed. 2007, 46, 1222-1244. [CrossRef] [PubMed]

29. Vangijzegem, T.; Stanicki, D.; Laurent, S. Magnetic iron oxide nanoparticles for drug delivery: Applications and characteristics. Expert Opin. Drug Deliv. 2019, 16, 69-78. [CrossRef]

30. El-Boubbou, K. Magnetic iron oxide nanoparticles as drug carriers: Preparation, conjugation and delivery. Nanomedicine 2018, 13, 929-952. [CrossRef]

31. Pham, H.N.; Pham, T.H.G.; Nguyen, D.T.; Phan, Q.T.; Le, T.T.H.; Ha, P.T.; Do, H.M.; Hoang, T.M.N.; Nguyen, X.P. Magnetic inductive heating of organs of mouse models treated by copolymer coated $\mathrm{Fe}_{3} \mathrm{O}_{4}$ nanoparticles. Adv. Nat. Sci. Nanosci. Nanotechnol. 2017, 8, 25013. [CrossRef]

32. Gao, L.; Zhuang, J.; Nie, L.; Zhang, J.; Zhang, Y.; Gu, N.; Wang, T.; Feng, J.; Yang, D.; Perrett, S.; et al. Intrinsic peroxidase-like activity of ferromagnetic nanoparticles. Nat. Nanotechnol. 2007, 2, 577-583. [CrossRef]

33. Wydra, R.J.; Oliver, C.E.; Anderson, K.W.; Dziubla, T.D.; Hilt, J.Z. Accelerated generation of free radicals by iron oxide nanoparticles in the presence of an alternating magnetic field. RSC Adv. 2015, 5, 18888-18893. [CrossRef] [PubMed]

34. Costa, R.C.C.; Moura, F.C.C.; Ardisson, J.D.; Fabris, J.D.; Lago, R.M. Highly active heterogeneous Fenton-like systems based on $\mathrm{Fe} 0 / \mathrm{Fe}_{3} \mathrm{O}_{4}$ composites prepared by controlled reduction of iron oxides. Appl. Catal. B Environ. 2008, 83, 131-139. [CrossRef]

35. Shin, S.; Yoon, H.; Jang, J. Polymer-encapsulated iron oxide nanoparticles as highly efficient Fenton catalysts. Catal. Commun. 2008, 10, 178-182. [CrossRef]

36. Chen, Z.; Yin, J.-J.; Zhou, Y.-T.; Zhang, Y.; Song, L.; Song, M.; Hu, S.; Gu, N. Dual enzyme-like activities of iron oxide nanoparticles and their implication for diminishing cytotoxicity. ACS Nano 2012, 6, 4001-4012. [CrossRef] [PubMed]

37. Niu, J.; Wang, K.; Kolattukudy, P.E. Cerium oxide nanoparticles inhibits oxidative stress and nuclear factor-kB activation in $\mathrm{H} 9 \mathrm{c} 2$ cardiomyocytes exposed to cigarette smoke extract. J. Pharmacol. Exp. Ther. 2011, 338, 53-61. [CrossRef] [PubMed]

38. Hall, G.; Hasday, J.D.; Rogers, T.B. Regulating the regulator: NF-kB signaling in heart. J. Mol. Cell. Cardiol. 2006, 41, 580-591. [CrossRef] [PubMed]

39. Jiang, N.; Dreher, K.L.; Dye, J.A.; Li, Y.; Richards, J.H.; Martin, L.D.; Adler, K.B. Residual oil fly ash induces cytotoxicity and mucin secretion by guinea pig tracheal epithelial cells via an oxidant-mediated mechanism. Toxicol. Appl. Pharmacol. 2000, 163, 221-230. [CrossRef] [PubMed]

40. Pagliari, F.; Mandoli, C.; Forte, G.; Magnani, E.; Pagliari, S.; Nardone, G.; Licoccia, S.; Minieri, M.; Di Nardo, P.; Traversa, E. Cerium oxide nanoparticles protect cardiac progenitor cells from oxidative stress. ACS Nano 2012, 6, 3767-3775. [CrossRef] [PubMed]

41. Liu, Q.; Zheng, J.; Guan, M.; Fang, X.; Wang, C.; Shu, C. Protective effect of C70-carboxyfullerene against oxidative-induced stress on postmitotic muscle cells. ACS Appl. Mater. Interfaces 2013, 5, 4328-4333. [CrossRef]

42. Shin, S.R.; Jung, S.M.; Zalabany, M.; Kim, K.; Zorlutuna, P.; bok Kim, S.; Nikkhah, M.; Khabiry, M.; Azize, M.; Kong, J.; et al. Carbon-nanotube-embedded hydrogel sheets for engineering cardiac constructs and bioactuators. ACS Nano 2013, 7, 2369-2380. [CrossRef] 
43. Minarchick, V.C.; Stapleton, P.A.; Sabolsky, E.M.; Nurkiewicz, T.R. Cerium dioxide nanoparticle exposure improves microvascular dysfunction and reduces oxidative stress in spontaneously hypertensive rats. Front. Physiol. 2015, 6, 339. [CrossRef] [PubMed]

44. Brito, R.; Castillo, G.; González, J.; Valls, N.; Rodrigo, R. Oxidative stress in hypertension: Mechanisms and therapeutic opportunities. Exp. Clin. Endocrinol. Diabetes 2015, 123, 325-335. [CrossRef] [PubMed]

45. Félétou, M.; Vanhoutte, P.M. Endothelial dysfunction: A multifaceted disorder (The Wiggers Award lecture). Am. J. Physiol. Circ. Physiol. 2006, 291, H985-H1002. [CrossRef] [PubMed]

46. Kolli, M.B.; Manne, N.D.P.K.; Para, R.; Nalabotu, S.K.; Nandyala, G.; Shokuhfar, T.; He, K.; Hamlekhan, A.; Ma, J.Y.; Wehner, P.S.; et al. Cerium oxide nanoparticles attenuate monocrotaline induced right ventricular hypertrophy following pulmonary arterial hypertension. Biomaterials 2014, 35, 9951-9962. [CrossRef] [PubMed]

47. Nassar, S.Z.; Hassaan, P.S.; Abdelmonsif, D.A.; ElAchy, S.N. Cardioprotective effect of cerium oxide nanoparticles in monocrotaline rat model of pulmonary hypertension: A possible implication of endothelin-1. Life Sci. 2018, 201, 89-101. [CrossRef] [PubMed]

48. Chan, S.Y.; Loscalzo, J. Pathogenic mechanisms of pulmonary arterial hypertension. J. Mol. Cell. Cardiol. 2008, 44, 14-30. [CrossRef] [PubMed]

49. Shiba, R.; Yanagisawa, M.; Miyauchi, T.; Ishii, Y.; Kimura, S.; Uchiyama, Y.; Masaki, T.; Goto, K. Elimination of intravenously injected endothelin-1 from the circulation of the rat. J. Cardiovasc. Pharmacol. 1989, 13 (Suppl. 5), S98-S101. [CrossRef] [PubMed]

50. Schwenke, D.O.; Pearson, J.T.; Sonobe, T.; Ishibashi-Ueda, H.; Shimouchi, A.; Kangawa, K.; Umetani, K.; Shirai, M. Role of Rho-kinase signaling and endothelial dysfunction in modulating blood flow distribution in pulmonary hypertension. J. Appl. Physiol. 2011, 110, 901-908. [CrossRef]

51. Xiong, F.; Wang, H.; Feng, Y.; Li, Y.; Hua, X.; Pang, X.; Zhang, S.; Song, L.; Zhang, Y.; Gu, N. Cardioprotective activity of iron oxide nanoparticles. Sci. Rep. 2015, 5, 8579. [CrossRef]

52. Hausenloy, D.J.; Yellon, D.M. Myocardial ischemia-reperfusion injury: A neglected therapeutic target. J. Clin. Investig. 2013, 123, 92-100. [CrossRef]

53. Han, J.; Kim, B.; Shin, J.Y.; Ryu, S.; Noh, M.; Woo, J.; Park, J.S.; Lee, Y.; Lee, N.; Hyeon, T.; et al. Iron oxide nanoparticle-mediated development of cellular gap junction crosstalk to improve mesenchymal stem cells' therapeutic efficacy for myocardial infarction. ACS Nano 2015, 9, 2805-2819. [CrossRef]

54. Hatzistergos, K.E.; Quevedo, H.; Oskouei, B.N.; Hu, Q.; Feigenbaum, G.S.; Margitich, I.S.; Mazhari, R.; Boyle, A.J.; Zambrano, J.P.; Rodriguez, J.E.; et al. Bone marrow mesenchymal stem cells stimulate cardiac stem cell proliferation and differentiation. Circ. Res. 2010, 107, 913-922. [CrossRef] [PubMed]

55. Mazhari, R.; Hare, J.M. Mechanisms of action of mesenchymal stem cells in cardiac repair: Potential influences on the cardiac stem cell niche. Nat. Clin. Pract. Cardiovasc. Med. 2007, 4, S21-S26. [CrossRef] [PubMed]

56. Gnecchi, M.; Zhang, Z.; Ni, A.; Dzau, V.J. Paracrine mechanisms in adult stem cell signaling and therapy. Circ. Res. 2008, 103, 1204-1219. [CrossRef] [PubMed]

57. Fukuhara, S.; Tomita, S.; Yamashiro, S.; Morisaki, T.; Yutani, C.; Kitamura, S.; Nakatani, T. Direct cell-cell interaction of cardiomyocytes is key for bone marrow stromal cells to go into cardiac lineage in vitro. J. Thorac. Cardiovasc. Surg. 2003, 125, 1470-1479. [CrossRef]

58. Murasawa, S.; Kawamoto, A.; Horii, M.; Nakamori, S.; Asahara, T. Niche-dependent translineage commitment of endothelial progenitor cells, not cell fusion in general, into myocardial lineage cells. Arterioscler. Thromb. Vasc. Biol. 2005, 25, 1388-1394. [CrossRef]

59. Song, D.; Liu, X.; Liu, R.; Yang, L.; Zuo, J.; Liu, W. Connexin 43 hemichannel regulates H9c2 cell proliferation by modulating intracellular ATP and $\left[\mathrm{Ca}^{2+}\right.$ ]. Acta Biochim. Biophys. Sin. 2010, 42, 472-482. [CrossRef]

60. Hahn, J.-Y.; Cho, H.-J.; Kang, H.-J.; Kim, T.-S.; Kim, M.-H.; Chung, J.-H.; Bae, J.-W.; Oh, B.-H.; Park, Y.-B.; Kim, H.-S. Pre-treatment of mesenchymal stem cells with a combination of growth factors enhances gap junction formation, cytoprotective effect on cardiomyocytes, and therapeutic efficacy for myocardial infarction. J. Am. Coll. Cardiol. 2008, 51, 933-943. [CrossRef]

61. Connell, J.P.; Augustini, E.; Moise, K.J.; Johnson, A.; Jacot, J.G. Formation of functional gap junctions in amniotic fluid-derived stem cells induced by transmembrane co-culture with neonatal rat cardiomyocytes. J. Cell. Mol. Med. 2013, 17, 774-781. [CrossRef] 
62. Naseroleslami, M.; Aboutaleb, N.; Parivar, K. The effects of superparamagnetic iron oxide nanoparticles-labeled mesenchymal stem cells in the presence of a magnetic field on attenuation of injury after heart failure. Drug Deliv. Transl. Res. 2018, 8, 1214-1225. [CrossRef]

63. Wadajkar, A.S.; Menon, J.U.; Kadapure, T.; Tran, R.T.; Nguyen, J.Y. and K.T. Design and application of magnetic-based theranostic nanoparticle systems. Recent Patents Biomed. Eng. 2013, 6, 47-57. [CrossRef] [PubMed]

64. Taylor, A.; Wilson, K.M.; Murray, P.; Fernig, D.G.; Lévy, R. Long-term tracking of cells using inorganic nanoparticles as contrast agents: Are we there yet? Chem. Soc. Rev. 2012, 41, 2707-2717. [CrossRef] [PubMed]

65. Mou, Y.; Zhou, J.; Xiong, F.; Li, H.; Sun, H.; Han, Y.; Gu, N.; Wang, C. Effects of 2,3-dimercaptosuccinic acid modified Fe2O3 nanoparticles on microstructure and biological activity of cardiomyocytes. RSC Adv. 2015, 5, 19493-19501. [CrossRef]

66. Mou, Y.; Lv, S.; Xiong, F.; Han, Y.; Zhao, Y.; Li, J.; Gu, N.; Zhou, J. Effects of different doses of 2,3-dimercaptosuccinic acid-modified $\mathrm{Fe}_{2} \mathrm{O}_{3}$ nanoparticles on intercalated discs in engineered cardiac tissues. J. Biomed. Mater. Res. Part B Appl. Biomater. 2018, 106, 121-130. [CrossRef] [PubMed]

67. Manring, H.R.; Dorn, L.E.; Ex-Willey, A.; Accornero, F.; Ackermann, M.A. At the heart of inter- and intracellular signaling: The intercalated disc. Biophys. Rev. 2018, 10, 961-971. [CrossRef] [PubMed]

68. Baker, M.; Robinson, S.D.; Lechertier, T.; Barber, P.R.; Tavora, B.; D’Amico, G.; Jones, D.T.; Vojnovic, B.; Hodivala-Dilke, K. Use of the mouse aortic ring assay to study angiogenesis. Nat. Protoc. 2012, 7, 89-104. [CrossRef]

69. Das, S.; Singh, S.; Dowding, J.M.; Oommen, S.; Kumar, A.; Sayle, T.X.T.; Saraf, S.; Patra, C.R.; Vlahakis, N.E.; Sayle, D.C.; et al. The induction of angiogenesis by cerium oxide nanoparticles through the modulation of oxygen in intracellular environments. Biomaterials 2012, 33, 7746-7755. [CrossRef]

70. Ishii, M.; Shibata, R.; Numaguchi, Y.; Kito, T.; Suzuki, H.; Shimizu, K.; Ito, A.; Honda, H.; Murohara, T. Enhanced angiogenesis by transplantation of mesenchymal stem cell sheet created by a novel magnetic tissue engineering method. Arterioscler. Thromb. Vasc. Biol. 2011, 31, 2210-2215. [CrossRef]

71. Yoshida, S.; Ono, M.; Shono, T.; Izumi, H.; Ishibashi, T.; Suzuki, H.; Kuwano, M. Involvement of interleukin-8, vascular endothelial growth factor, and basic fibroblast grow th factor in tumor necrosis factor alpha-dependent angiogenesis. Mol. Cell. Biol. 1997, 17, 4015-4023. [CrossRef]

72. Leung, K.-W.; Ng, H.-M.; Tang, M.K.S.; Wong, C.C.K.; Wong, R.N.S.; Wong, A.S.T. Ginsenoside-Rg1 mediates a hypoxia-independent upregulation of hypoxia-inducible factor- $1 \alpha$ to promote angiogenesis. Angiogenesis 2011, 14, 515-522. [CrossRef]

73. Patra, C.R.; Kim, J.H.; Pramanik, K.; D’Uscio, L.V.; Patra, S.; Pal, K.; Ramchandran, R.; Strano, M.S.; Mukhopadhyay, D. Reactive oxygen species driven angiogenesis by inorganic nanorods. Nano Lett. 2011, 11, 4932-4938. [CrossRef] [PubMed]

74. Claffey, K.P.; Brown, L.F.; del Aguila, L.F.; Tognazzi, K.; Yeo, K.T.; Manseau, E.J.; Dvorak, H.F. Expression of vascular permeability factor/vascular endothelial growth factor by melanoma cells increases tumor growth, angiogenesis, and experimental metastasis. Cancer Res. 1996, 56, 172-181. [PubMed]

75. Kajiguchi, M.; Kondo, T.; Izawa, H.; Kobayashi, M.; Yamamoto, K.; Shintani, S.; Numaguchi, Y.; Naoe, T.; Takamatsu, J.; Komori, K.; et al. Safety and efficacy of autologous progenitor cell transplantation for therapeutic angiogenesis in patients with critical limb ischemia. Circ. J. 2007, 71, 196-201. [CrossRef] [PubMed]

76. Matoba, S.; Tatsumi, T.; Murohara, T.; Imaizumi, T.; Katsuda, Y.; Ito, M.; Saito, Y.; Uemura, S.; Suzuki, H.; Fukumoto, S.; et al. Long-term clinical outcome after intramuscular implantation of bone marrow mononuclear cells (therapeutic angiogenesis by cell transplantation [TACT] trial) in patients with chronic limb ischemia. Am. Heart J. 2008, 156, 1010-1018. [CrossRef] [PubMed]

77. Heeschen, C.; Lehmann, R.; Honold, J.; Assmus, B.; Aicher, A.; Walter, D.H.; Martin, H.; Zeiher, A.M.; Dimmeler, S. Profoundly reduced neovascularization capacity of bone marrow mononuclear cells derived from patients with chronic ischemic jeart disease. Circulation 2004, 109, 1615-1622. [CrossRef] [PubMed]

78. Kuchibhatla, S.V.N.T.; Karakoti, A.S.; Sayle, D.C.; Heinrich, H.; Seal, S. Symmetry-driven spontaneous self-assembly of nanoscale ceria building blocks to fractal superoctahedra. Cryst. Growth Des. 2009, 9, 1614-1620. [CrossRef] 
79. Recillas, S.; Colón, J.; Casals, E.; González, E.; Puntes, V.; Sánchez, A.; Font, X. Chromium VI adsorption on cerium oxide nanoparticles and morphology changes during the process. J. Hazard. Mater. 2010, 184, 425-431. [CrossRef]

80. Karakoti, A.S.; Kuchibhatla, S.V.N.T.; Baer, D.R.; Thevuthasan, S.; Sayle, D.C.; Seal, S. Self-assembly of cerium oxide nanostructures in ice molds. Small 2008, 4, 1210-1216. [CrossRef]

81. McGonigle, S.; Shifrin, V. In vitro assay of angiogenesis: Inhibition of capillary tube formation. Curr. Protoc. Pharmacol. 2008, 43. [CrossRef]

82. Ushio-Fukai, M. Redox signaling in angiogenesis: Role of NADPH oxidase. Cardiovasc. Res. 2006, 71, $226-235$. [CrossRef]

83. Facciabene, A.; Peng, X.; Hagemann, I.S.; Balint, K.; Barchetti, A.; Wang, L.-P.; Gimotty, P.A.; Gilks, C.B.; Lal, P.; Zhang, L.; et al. Tumour hypoxia promotes tolerance and angiogenesis via CCL28 and Treg cells. Nature 2011, 475, 226-230. [CrossRef] [PubMed]

84. Nethi, S.K.; Nanda, H.S.; Steele, T.W.J.; Patra, C.R. Functionalized nanoceria exhibit improved angiogenic properties. J. Mater. Chem. B 2017, 5, 9371-9383. [CrossRef]

85. Cipitria, A.; Boettcher, K.; Schoenhals, S.; Garske, D.S.; Schmidt-Bleek, K.; Ellinghaus, A.; Dienelt, A.; Peters, A.; Mehta, M.; Madl, C.M.; et al. In-situ tissue regeneration through SDF-1 $\alpha$ driven cell recruitment and stiffness-mediated bone regeneration in a critical-sized segmental femoral defect. Acta Biomater. 2017, 60, 50-63. [CrossRef] [PubMed]

86. Augustine, R.; Dalvi, Y.B.; Dan, P.; George, N.; Helle, D.; Varghese, R.; Thomas, S.; Menu, P.; Sandhyarani, N. Nanoceria can act as the cues for angiogenesis in tissue-engineering scaffolds: Toward next-generation in situ tissue engineering. ACS Biomater. Sci. Eng. 2018, 4, 4338-4353. [CrossRef]

87. Tang, Y.L.; Tang, Y.; Zhang, Y.C.; Qian, K.; Shen, L.; Phillips, M.I. Improved graft mesenchymal stem cell survival in ischemic heart with a hypoxia-regulated heme oxygenase-1 vector. J. Am. Coll. Cardiol. 2005, 46, 1339-1350. [CrossRef] [PubMed]

88. Zhang, M.; Methot, D.; Poppa, V.; Fujio, Y.; Walsh, K.; Murry, C.E. Cardiomyocyte grafting for cardiac repair: Graft cell death and anti-death strategies. J. Mol. Cell. Cardiol. 2001, 33, 907-921. [CrossRef] [PubMed]

89. Pittenger, M.F.; Martin, B.J. Mesenchymal stem cells and their potential as cardiac therapeutics. Circ. Res. 2004, 95, 9-20. [CrossRef] [PubMed]

90. Kinnaird, T.; Stabile, E.; Burnett, M.S.; Shou, M.; Lee, C.W.; Barr, S.; Fuchs, S.; Epstein, S.E. Local delivery of marrow-derived stromal cells augments collateral perfusion through paracrine mechanisms. Circulation 2004, 109, 1543-1549. [CrossRef] [PubMed]

91. Ishii, M.; Numaguchi, Y.; Okumura, K.; Kubota, R.; Ma, X.; Murakami, R.; Naruse, K.; Murohara, T. Mesenchymal stem cell-based gene therapy with prostacyclin synthase enhanced neovascularization in hindlimb ischemia. Atherosclerosis 2009, 206, 109-118. [CrossRef]

92. Kito, T.; Shibata, R.; Ishii, M.; Suzuki, H.; Himeno, T.; Kataoka, Y.; Yamamura, Y.; Yamamoto, T.; Nishio, N.; Ito, $\mathrm{S}$; et al. iPS cell sheets created by a novel magnetite tissue engineering method for reparative angiogenesis. Sci. Rep. 2013, 3, 1418. [CrossRef]

93. Suzuki, H.; Shibata, R.; Kito, T.; Ishii, M.; Li, P.; Yoshikai, T.; Nishio, N.; Ito, S.; Numaguchi, Y.; Yamashita, J.K.; et al. Therapeutic angiogenesis by transplantation of induced pluripotent stem cell-derived Flk-1 positive cells. BMC Cell Biol. 2010, 11, 72. [CrossRef] [PubMed]

94. Oryan, A.; Alidadi, S.; Moshiri, A.; Maffulli, N. Bone regenerative medicine: Classic options, novel strategies, and future directions. J. Orthop. Surg. Res. 2014, 9, 18. [CrossRef] [PubMed]

95. Ma, P.X. Scaffolds for tissue fabrication. Mater. Today 2004, 7, 30-40. [CrossRef]

96. Chan, W.D.; Perinpanayagam, H.; Goldberg, H.A.; Hunter, G.K.; Dixon, S.J.; Santos, G.C.; Rizkalla, A.S. Tissue engineering scaffolds for the regeneration of craniofacial bone. J. Can. Dent. Assoc. 2009, 75, 373-377. [PubMed]

97. Langer, R.; Vacanti, J. Tissue engineering. Science 1993, 260, 920-926. [CrossRef]

98. Benoit, D.S.W.; Anseth, K.S. The effect on osteoblast function of colocalized RGD and PHSRN epitopes on PEG surfaces. Biomaterials 2005, 26, 5209-5220. [CrossRef]

99. Gómez, G.; Korkiakoski, S.; González, M.M.; Länsman, S.; Ellä, V.; Salo, T.; Kellomäki, M.; Ashammakhi, N.; Arnaud, E. Effect of FGF and polylactide scaffolds on calvarial bone healing with growth factor on biodegradable polymer scaffolds. J. Craniofac. Surg. 2006, 17, 935-942. [CrossRef] 
100. Tachibana, A.; Nishikawa, Y.; Nishino, M.; Kaneko, S.; Tanabe, T.; Yamauchi, K. Modified keratin sponge: Binding of bone morphogenetic protein-2 and osteoblast differentiation. J. Biosci. Bioeng. 2006, 102, 425-429. [CrossRef]

101. Karakoti, A.S.; Tsigkou, O.; Yue, S.; Lee, P.D.; Stevens, M.M.; Jones, J.R.; Seal, S. Rare earth oxides as nanoadditives in 3-D nanocomposite scaffolds for bone regeneration. J. Mater. Chem. 2010, $20,8912$. [CrossRef]

102. Jones, J.R.; Ehrenfried, L.M.; Hench, L.L. Optimising bioactive glass scaffolds for bone tissue engineering. Biomaterials 2006, 27, 964-973. [CrossRef]

103. Gough, J.E.; Jones, J.R.; Hench, L.L. Nodule formation and mineralisation of human primary osteoblasts cultured on a porous bioactive glass scaffold. Biomaterials 2004, 25, 2039-2046. [CrossRef] [PubMed]

104. Orimo, $\mathrm{H}$. The mechanism of mineralization and the role of alkaline phosphatase in health and disease. J. Nippon Med. Sch. 2010, 77, 4-12. [CrossRef] [PubMed]

105. Nicolini, V.; Gambuzzi, E.; Malavasi, G.; Menabue, L.; Menziani, M.C.; Lusvardi, G.; Pedone, A.; Benedetti, F.; Luches, P.; D'Addato, S.; et al. Evidence of catalase mimetic activity in $\mathrm{Ce}^{3+} / \mathrm{Ce}^{4+}$ doped bioactive glasses. J. Phys. Chem. B 2015, 119, 4009-4019. [CrossRef] [PubMed]

106. Nicolini, V.; Varini, E.; Malavasi, G.; Menabue, L.; Menziani, M.C.; Lusvardi, G.; Pedone, A.; Benedetti, F.; Luches, $\mathrm{P}$. The effect of composition on structural, thermal, redox and bioactive properties of Ce-containing glasses. Mater. Des. 2016, 97, 73-85. [CrossRef]

107. Deliormanl1, A.M. Electrospun cerium and gallium-containing silicate based 13-93 bioactive glass fibers for biomedical applications. Ceram. Int. 2016, 42, 897-906. [CrossRef]

108. Farias, I.A.P.; Dos Santos, C.C.L.; Sampaio, F.C. Antimicrobial Activity of Cerium Oxide Nanoparticles on Opportunistic Microorganisms: A Systematic Review. Biomed. Res. Int. 2018, 2018, 1923606. [CrossRef] [PubMed]

109. Lu, B.; Zhu, D.-Y.; Yin, J.-H.; Xu, H.; Zhang, C.-Q.; Ke, Q.-F.; Gao, Y.-S.; Guo, Y.-P. Incorporation of cerium oxide in hollow mesoporous bioglass scaffolds for enhanced bone regeneration by activating the ERK signaling pathway. Biofabrication 2019, 11, 25012. [CrossRef] [PubMed]

110. You, M.; Li, K.; Xie, Y.; Huang, L.; Zheng, X. The effects of cerium valence states at cerium oxide coatings on the responses of bone mesenchymal stem cells and macrophages. Biol. Trace Elem. Res. 2017, 179, 259-270. [CrossRef] [PubMed]

111. Li, K.; Yu, J.; Xie, Y.; You, M.; Huang, L.; Zheng, X. The effects of cerium oxide incorporation in calcium silicate coating on bone mesenchymal stem cell and macrophage responses. Biol. Trace Elem. Res. 2017, 177, 148-158. [CrossRef]

112. Naganuma, T.; Traversa, E. The effect of cerium valence states at cerium oxide nanoparticle surfaces on cell proliferation. Biomaterials 2014, 35, 4441-4453. [CrossRef]

113. Li, K.; Shen, Q.; Xie, Y.; You, M.; Huang, L.; Zheng, X. Incorporation of cerium oxide into hydroxyapatite coating protects bone marrow stromal cells against $\mathrm{H}_{2} \mathrm{O}_{2}$-induced inhibition of osteogenic differentiation. Biol. Trace Elem. Res. 2018, 182, 91-104. [CrossRef] [PubMed]

114. Carmeliet, P.; Jain, R.K. Molecular mechanisms and clinical applications of angiogenesis. Nature 2011, 473, 298. [CrossRef] [PubMed]

115. Xiang, J.; Li, J.; He, J.; Tang, X.; Dou, C.; Cao, Z.; Yu, B.; Zhao, C.; Kang, F.; Yang, L.; et al. Cerium oxide nanoparticle modified scaffold interface enhances vascularization of bone grafts by activating calcium channel of mesenchymal stem cells. ACS Appl. Mater. Interfaces 2016, 8, 4489-4499. [CrossRef] [PubMed]

116. Yuan, G.; Nanduri, J.; Khan, S.; Semenza, G.L.; Prabhakar, N.R. Induction of HIF-1 $\alpha$ expression by intermittent hypoxia: Involvement of NADPH oxidase, $\mathrm{Ca}^{2+}$ signaling, prolyl hydroxylases, and mTOR. J. Cell. Physiol. 2008, 217, 674-685. [CrossRef] [PubMed]

117. Oda, S.; Oda, T.; Takabuchi, S.; Nishi, K.; Wakamatsu, T.; Tanaka, T.; Adachi, T.; Fukuda, K.; Nohara, R.; Hirota, K. The calcium channel blocker cilnidipine selectively suppresses hypoxia-inducible factor 1 activity in vascular cells. Eur. J. Pharmacol. 2009, 606, 130-136. [CrossRef] [PubMed]

118. Kim, K.H.; Kim, D.; Park, J.Y.; Jung, H.J.; Cho, Y.-H.; Kim, H.K.; Han, J.; Choi, K.-Y.; Kwon, H.J. NNC 55-0396, a T-type $\mathrm{Ca}^{2+}$ channel inhibitor, inhibits angiogenesis via suppression of hypoxia-inducible factor- $1 \alpha$ signal transduction. J. Mol. Med. 2015, 93, 499-509. [CrossRef] [PubMed] 
119. Rotter, N.; Ung, F.; Roy, A.K.; Vacanti, M.; Eavey, R.D.; Vacanti, C.A.; Bonassar, L.J. Role for interleukin $1 \alpha$ in the inhibition of chondrogenesis in autologous implants using polyglycolic acid-polylactic acid scaffolds. Tissue Eng. 2005, 11, 192-200. [CrossRef]

120. Hung, C.T.; Mauck, R.L.; Wang, C.C.-B.; Lima, E.G.; Ateshian, G.A. A paradigm for functional tissue engineering of articular cartilage via applied physiologic deformational loading. Ann. Biomed. Eng. 2004, 32, 35-49. [CrossRef]

121. Capito, R.M.; Spector, M. Scaffold-based articular cartilage repair - Future prospects wedding gene therapy and tissue engineering. IEEE Eng. Med. Biol. Mag. 2003, 22, 42-50. [CrossRef]

122. Habibovic, P.; Woodfield, T.; de Groot, K.; van Blitterswijk, C. Predictive value of in vitro and in vivo assays in bone and cartilage repair-What do they really tell us about the clinical performance. In Advances in Experimental Medicine and Biology; Fisher, J.P., Ed.; Springer Science + Business Media, LLC: Boston, MA, USA, 2006; Volume 585, pp. 327-360.

123. Ponnurangam, S.; O'Connell, G.D.; Chernyshova, I.V.; Wood, K.; Hung, C.T.-H.; Somasundaran, P. Beneficial effects of cerium oxide nanoparticles in development of chondrocyte-seeded hydrogel constructs and cellular response to interleukin insults. Tissue Eng. Part A 2014, 20, 2908-2919. [CrossRef]

124. Benton, H.P.; Tyler, J.A. Inhibition of cartilage proteoglycan synthesis by interleukin 1. Biochem. Biophys. Res. Commun. 1988, 154, 421-428. [CrossRef]

125. Lima, E.G.; Tan, A.R.; Tai, T.; Bian, L.; Stoker, A.M.; Ateshian, G.A.; Cook, J.L.; Hung, C.T. Differences in interleukin-1 response between engineered and native cartilage. Tissue Eng. Part A 2008, 14, 1721-1730. [CrossRef] [PubMed]

126. Tyler, J.A. Insulin-like growth factor 1 can decrease degradation and promote synthesis of proteoglycan in cartilage exposed to cytokines. Biochem. J. 1989, 260, 543-548. [CrossRef] [PubMed]

127. Xia, Y.; Chen, H.; Zhang, F.; Wang, L.; Chen, B.; Reynolds, M.A.; Ma, J.; Schneider, A.; Gu, N.; Xu, H.H.K. Injectable calcium phosphate scaffold with iron oxide nanoparticles to enhance osteogenesis via dental pulp stem cells. Artif. Cells Nanomed. Biotechnol. 2018, 46, 423-433. [CrossRef] [PubMed]

128. Xu, H.H.K.; Quinn, J.B.; Takagi, S.; Chow, L.C. Processing and properties of strong and non-rigid calcium phosphate cement. J. Dent. Res. 2002, 81, 219-224. [CrossRef] [PubMed]

129. d'Aquino, R.; Papaccio, G.; Laino, G.; Graziano, A. Dental pulp stem cells: A promising tool for bone regeneration. Stem Cell Rev. 2008, 4, 21-26. [CrossRef] [PubMed]

130. Gronthos, S.; Mankani, M.; Brahim, J.; Robey, P.G.; Shi, S. Postnatal human dental pulp stem cells (DPSCs) in vitro and in vivo. Proc. Natl. Acad. Sci. USA 2000, 97, 13625-13630. [CrossRef] [PubMed]

131. Xia, Y.; Chen, H.; Zhao, Y.; Zhang, F.; Li, X.; Wang, L.; Weir, M.D.; Ma, J.; Reynolds, M.A.; Gu, N.; et al. Novel magnetic calcium phosphate-stem cell construct with magnetic field enhances osteogenic differentiation and bone tissue engineering. Mater. Sci. Eng. C 2019, 98, 30-41. [CrossRef] [PubMed]

132. Wang, H.; Zhao, S.; Zhou, J.; Zhu, K.; Cui, X.; Huang, W.; Rahaman, M.N.; Zhang, C.; Wang, D. Biocompatibility and osteogenic capacity of borosilicate bioactive glass scaffolds loaded with $\mathrm{Fe}_{3} \mathrm{O}_{4}$ magnetic nanoparticles. J. Mater. Chem. B 2015, 3, 4377-4387. [CrossRef]

133. Lai, W.-Y.; Feng, S.-W.; Chan, Y.-H.; Chang, W.-J.; Wang, H.-T.; Huang, H.-M. In Vivo Investigation into Effectiveness of $\mathrm{Fe}_{3} \mathrm{O}_{4} /$ PLLA Nanofibers for Bone Tissue Engineering Applications. Polymers 2018, 10, 804. [CrossRef] [PubMed]

134. Cojocaru, F.D.; Balan, V.; Popa, M.I.; Lobiuc, A.; Antoniac, A.; Antoniac, I.V.; Verestiuc, L. Biopolymers-Calcium phosphates composites with inclusions of magnetic nanoparticles for bone tissue engineering. Int. J. Biol. Macromol. 2019, 125, 612-620. [CrossRef] [PubMed]

135. Wang, H.-T.; Chiang, P.-C.; Tzeng, J.-J.; Wu, T.-L.; Pan, Y.-H.; Chang, W.-J.; Huang, H.-M. In vitro biocompatibility, radiopacity, and physical property tests of nano- $\mathrm{Fe}_{3} \mathrm{O}_{4}$ incorporated poly-l-lactide bone screws. Polymers 2017, 9, 191. [CrossRef] [PubMed]

136. Chang, W.J.; Pan, Y.H.; Tzeng, J.J.; Wu, T.L.; Fong, T.H.; Feng, S.W.; Huang, H.M. Development and testing of X-ray imaging-enhanced poly-l-lactide bone screws. PLoS ONE 2015, 10, e0140354. [CrossRef] [PubMed]

137. Pan, Y.-H.; Wang, H.-T.; Wu, T.-L.; Fan, K.-H.; Huang, H.-M.; Chang, W.-J. Fabrication of Fe $\mathrm{O}_{4} / \mathrm{PLLA}$ composites for use in bone tissue engineering. Polym. Compos. 2017, 38, 2881-2888. [CrossRef]

138. Chen, H.; Sun, J.; Wang, Z.; Zhou, Y.; Lou, Z.; Chen, B.; Wang, P.; Guo, Z.; Tang, H.; Ma, J.; et al. Magnetic cell-scaffold interface constructed by superparamagnetic IONP enhanced osteogenesis of adipose-derived stem cells. ACS Appl. Mater. Interfaces 2018, 10, 44279-44289. [CrossRef] 
139. Yan, Y.; Zhang, Y.; Zuo, Y.; Zou, Q.; Li, J.; Li, Y. Development of $\mathrm{Fe}_{3} \mathrm{O}_{4}-\mathrm{HA} / \mathrm{PU}$ superparamagnetic composite porous scaffolds for bone repair application. Mater. Lett. 2018, 212, 303-306. [CrossRef]

140. Meng, J.; Zhang, Y.; Qi, X.; Kong, H.; Wang, C.; Xu, Z.; Xie, S.; Gu, N.; Xu, H. Paramagnetic nanofibrous composite films enhance the osteogenic responses of pre-osteoblast cells. Nanoscale 2010, 2, 2565-2569. [CrossRef]

141. Meng, J.; Xiao, B.; Zhang, Y.; Liu, J.; Xue, H.; Lei, J.; Kong, H.; Huang, Y.; Jin, Z.; Gu, N.; et al. Super-paramagnetic responsive nanofibrous scaffolds under static magnetic field enhance osteogenesis for bone repair in vivo. Sci. Rep. 2013, 3, 2655. [CrossRef]

142. Hao, S.; Meng, J.; Zhang, Y.; Liu, J.; Nie, X.; Wu, F.; Yang, Y.; Wang, C.; Gu, N.; Xu, H. Macrophage phenotypic mechanomodulation of enhancing bone regeneration by superparamagnetic scaffold upon magnetization. Biomaterials 2017, 140, 16-25. [CrossRef]

143. Hu, S.; Zhou, Y.; Zhao, Y.; Xu, Y.; Zhang, F.; Gu, N.; Ma, J.; Reynolds, M.A.; Xia, Y.; Xu, H.H.K. Enhanced bone regeneration and visual monitoring via superparamagnetic iron oxide nanoparticle scaffold in rats. J. Tissue Eng. Regen. Med. 2018, 12, e2085-e2098. [CrossRef]

144. Yuan, Z.; Memarzadeh, K.; Stephen, A.S.; Allaker, R.P.; Brown, R.A.; Huang, J. Development of a 3D collagen model for the in vitro evaluation of magnetic-assisted osteogenesis. Sci. Rep. 2018, 8, 16270. [CrossRef] [PubMed]

145. Brown, R.A.; Wiseman, M.; Chuo, C.-B.; Cheema, U.; Nazhat, S.N. Ultrarapid engineering of biomimetic materials and tissues: Fabrication of nano- and microstructures by plastic compression. Adv. Funct. Mater. 2005, 15, 1762-1770. [CrossRef]

146. Buxton, P.G.; Bitar, M.; Gellynck, K.; Parkar, M.; Brown, R.A.; Young, A.M.; Knowles, J.C.; Nazhat, S.N. Dense collagen matrix accelerates osteogenic differentiation and rescues the apoptotic response to MMP inhibition. Bone 2008, 43, 377-385. [CrossRef] [PubMed]

147. Huang, Z.; Wu, Z.; Ma, B.; Yu, L.; He, Y.; Xu, D.; Wu, Y.; Wang, H.; Qiu, G. Enhanced in vitro biocompatibility and osteogenesis of titanium substrates immobilized with dopamine-assisted superparamagnetic $\mathrm{Fe}_{3} \mathrm{O}_{4}$ nanoparticles for hBMSCs. R. Soc. Open Sci. 2018, 5, 172033. [CrossRef] [PubMed]

148. Zhuang, J.; Lin, S.; Dong, L.; Cheng, K.; Weng, W. Magnetically actuated mechanical stimuli on $\mathrm{Fe}_{3} \mathrm{O}_{4} /$ mineralized collagen coatings to enhance osteogenic differentiation of the MC3T3-E1 cells. Acta Biomater. 2018, 71, 49-60. [CrossRef] [PubMed]

149. Wang, Q.; Chen, B.; Cao, M.; Sun, J.; Wu, H.; Zhao, P.; Xing, J.; Yang, Y.; Zhang, X.; Ji, M.; et al. Response of MAPK pathway to iron oxide nanoparticles in vitro treatment promotes osteogenic differentiation of hBMSCs. Biomaterials 2016, 86, 11-20. [CrossRef] [PubMed]

150. Sun, J.; Liu, X.; Huang, J.; Song, L.; Chen, Z.; Liu, H.; Li, Y.; Zhang, Y.; Gu, N. Magnetic assembly-mediated enhancement of differentiation of mouse bone marrow cells cultured on magnetic colloidal assemblies. Sci. Rep. 2015, 4, 5125. [CrossRef] [PubMed]

151. Barrientos, S.; Stojadinovic, O.; Golinko, M.S.; Brem, H.; Tomic-Canic, M. Perspective article: Growth factors and cytokines in wound healing. Wound Repair Regen. 2008, 16, 585-601. [CrossRef] [PubMed]

152. Schäfer, M.; Werner, S. Oxidative stress in normal and impaired wound repair. Pharmacol. Res. 2008, 58, 165-171. [CrossRef] [PubMed]

153. Mandoli, C.; Pagliari, F.; Pagliari, S.; Forte, G.; Di Nardo, P.; Licoccia, S.; Traversa, E. Stem cell aligned growth induced by $\mathrm{CeO}_{2}$ nanoparticles in PLGA scaffolds with improved bioactivity for regenerative medicine. Adv. Funct. Mater. 2010, 20, 1617-1624. [CrossRef]

154. Chigurupati, S.; Mughal, M.R.; Okun, E.; Das, S.; Kumar, A.; McCaffery, M.; Seal, S.; Mattson, M.P. Effects of cerium oxide nanoparticles on the growth of keratinocytes, fibroblasts and vascular endothelial cells in cutaneous wound healing. Biomaterials 2013, 34, 2194-2201. [CrossRef] [PubMed]

155. Rasik, A.M.; Shukla, A. Antioxidant status in delayed healing type of wounds. Int. J. Exp. Pathol. 2001, 81, 257-263. [CrossRef] [PubMed]

156. Dowding, J.M.; Dosani, T.; Kumar, A.; Seal, S.; Self, W.T. Cerium oxide nanoparticles scavenge nitric oxide radical (NO). Chem. Commun. 2012, 48, 4896-4898. [CrossRef] [PubMed]

157. Huang, X.; Li, L.-D.; Lyu, G.-M.; Shen, B.-Y.; Han, Y.-F.; Shi, J.-L.; Teng, J.-L.; Feng, L.; Si, S.-Y.; Wu, J.-H.; et al. Chitosan-coated cerium oxide nanocubes accelerate cutaneous wound healing by curtailing persistent inflammation. Inorg. Chem. Front. 2018, 5, 386-393. [CrossRef] 
158. Pyun, D.G.; Choi, H.J.; Yoon, H.S.; Thambi, T.; Lee, D.S. Polyurethane foam containing rhEGF as a dressing material for healing diabetic wounds: Synthesis, characterization, in vitro and in vivo studies. Colloids Surf. B 2015, 135, 699-706. [CrossRef] [PubMed]

159. Zgheib, C.; Hilton, S.A.; Dewberry, L.C.; Hodges, M.M.; Ghatak, S.; Xu, J.; Singh, S.; Roy, S.; Sen, C.K.; Seal, S.; et al. Use of cerium oxide nanoparticles conjugated with microRNA-146a to correct the diabetic wound healing impairment. J. Am. Coll. Surg. 2019, 228, 107-115. [CrossRef] [PubMed]

160. Bhatt, K.; Lanting, L.L.; Jia, Y.; Yadav, S.; Reddy, M.A.; Magilnick, N.; Boldin, M.; Natarajan, R. Anti-inflammatory role of microRNA-146a in the pathogenesis of diabetic nephropathy. J. Am. Soc. Nephrol. 2016, 27, 2277-2288. [CrossRef] [PubMed]

161. Xu, J.; Wu, W.; Zhang, L.; Dorset-Martin, W.; Morris, M.W.; Mitchell, M.E.; Liechty, K.W. The role of microRNA-146a in the pathogenesis of the diabetic wound-healing impairment. Diabetes 2012, 61, 2906-2912. [CrossRef]

162. Feng, Y.; Chen, L.; Luo, Q.; Wu, M.; Chen, Y.; Shi, X. Involvement of microRNA-146a in diabetic peripheral neuropathy through the regulation of inflammation. Drug Des. Dev. Ther. 2018, 12, 171-177. [CrossRef]

163. Kobyliak, N.; Abenavoli, L.; Kononenko, L.; Kyriienko, D.; Spivak, M. Neuropathic diabetic foot ulcers treated with cerium dioxide nanoparticles: A case report. Diabetes Metab. Syndr. Clin. Res. Rev. 2019, 13, 228-234. [CrossRef]

164. Chong, E.J.; Phan, T.T.; Lim, I.J.; Zhang, Y.Z.; Bay, B.H.; Ramakrishna, S.; Lim, C.T. Evaluation of electrospun PCL/gelatin nanofibrous scaffold for wound healing and layered dermal reconstitution. Acta Biomater. 2007, 3, 321-330. [CrossRef] [PubMed]

165. Rather, H.A.; Thakore, R.; Singh, R.; Jhala, D.; Singh, S.; Vasita, R. Antioxidative study of Cerium Oxide nanoparticle functionalised PCL-Gelatin electrospun fibers for wound healing application. Bioact. Mater. 2018, 3, 201-211. [CrossRef] [PubMed]

166. Naseri-Nosar, M.; Farzamfar, S.; Sahrapeyma, H.; Ghorbani, S.; Bastami, F.; Vaez, A.; Salehi, M. Cerium oxide nanoparticle-containing poly ( $\varepsilon$-caprolactone)/gelatin electrospun film as a potential wound dressing material: In vitro and in vivo evaluation. Mater. Sci. Eng. C 2017, 81, 366-372. [CrossRef] [PubMed]

167. Eming, S.A.; Martin, P.; Tomic-Canic, M. Wound repair and regeneration: Mechanisms, signaling, and translation. Sci. Transl. Med. 2014, 6, 265sr6. [CrossRef] [PubMed]

168. Gurtner, G.C.; Werner, S.; Barrandon, Y.; Longaker, M.T. Wound repair and regeneration. Nature 2008, 453, 314. [CrossRef] [PubMed]

169. Forbes, S.J.; Rosenthal, N. Preparing the ground for tissue regeneration: From mechanism to therapy. Nat. Med. 2014, 20, 857. [CrossRef]

170. Wu, H.; Li, F.; Wang, S.; Lu, J.; Li, J.; Du, Y.; Sun, X.; Chen, X.; Gao, J.; Ling, D. Ceria nanocrystals decorated mesoporous silica nanoparticle based ROS-scavenging tissue adhesive for highly efficient regenerative wound healing. Biomaterials 2018, 151, 66-77. [CrossRef]

171. Loo, A.E.K.; Wong, Y.T.; Ho, R.; Wasser, M.; Du, T.; Ng, W.T.; Halliwell, B. Effects of hydrogen peroxide on wound healing in mice in relation to oxidative damage. PLoS ONE 2012, 7, e49215. [CrossRef]

172. Sen, C.K. Wound healing essentials: Let there be oxygen. Wound Repair Regen. 2009, 17, 1-18. [CrossRef]

173. Hu, M.; Korschelt, K.; Daniel, P.; Landfester, K.; Tremel, W.; Bannwarth, M.B. Fibrous nanozymes dressings with catalase-like activity for $\mathrm{H}_{2} \mathrm{O}_{2}$ reduction to promote wound healing. ACS Appl. Mater. Interfaces 2017, 9, 38024-38031. [CrossRef]

174. Casco, M.; Olsen, T.; Herbst, A.; Evans, G.; Rothermel, T.; Pruett, L.; Simionescu, D.; Visconti, R.; Alexis, F. Iron oxide nanoparticles stimulates extra-cellular matrix production in cellular spheroids. Bioengineering 2017, 4, 4. [CrossRef] [PubMed]

175. Mattix, B.; Olsen, T.R.; Gu, Y.; Casco, M.; Herbst, A.; Simionescu, D.T.; Visconti, R.P.; Kornev, K.G.; Alexis, F. Biological magnetic cellular spheroids as building blocks for tissue engineering. Acta Biomater. 2014, 10, 623-629. [CrossRef] [PubMed]

176. Mi, F.-L.; Shyu, S.-S.; Wu, Y.-B.; Lee, S.-T.; Shyong, J.-Y.; Huang, R.-N. Fabrication and characterization of a sponge-like asymmetric chitosan membrane as a wound dressing. Biomaterials 2001, 22, 165-173. [CrossRef]

177. Hao, S.; Zhang, Y.; Meng, J.; Liu, J.; Wen, T.; Gu, N.; Xu, H. Integration of a superparamagnetic scaffold and magnetic field to enhance the wound-healing phenotype of fibroblasts. ACS Appl. Mater. Interfaces 2018, 10, 22913-22923. [CrossRef] [PubMed] 
178. Hoffman, T.; Khademhosseini, A.; Langer, R. Chasing the paradigm: Clinical translation of 25 years of tissue engineering. Tissue Eng. Part A 2019, 25, 679-687. [CrossRef] [PubMed]

179. Geris, L.; Papantoniou, I. The third era of tissue engineering: Reversing the innovation drivers. Tissue Eng. Part A 2019, 25, 821-826. [CrossRef] [PubMed]

180. Patil, S.U.; Adireddy, S.; Jaiswal, A.; Mandava, S.; Lee, R.B.; Chrisey, B.D. In vitro/in vivo toxicity evaluation and quantification of iron oxide nanoparticles. Int. J. Mol. Sci. 2015, 16, 24417-24450. [CrossRef] [PubMed]

181. Yokel, R.A.; Hussain, S.; Garantziotis, S.; Demokritou, P.; Castranova, V.; Cassee, F.R. The yin: An adverse health perspective of nanoceria: Uptake, distribution, accumulation, and mechanisms of its toxicity. Environ. Sci. Nano 2014, 1, 406-428. [CrossRef]

182. Hirst, S.M.; Karakoti, A.; Singh, S.; Self, W.; Tyler, R.; Seal, S.; Reilly, C.M. Bio-distribution and in vivo antioxidant effects of cerium oxide nanoparticles in mice. Environ. Toxicol. 2013, 28, 107-118. [CrossRef]

183. Schlachter, E.K.; Widmer, H.R.; Bregy, A.; Lonnfors-Weitzel, T.; Vajtai, I.; Corazza, N.; Bernau, V.J.P.; Weitzel, T.; Mordasini, P.; Slotboom, J.; et al. Metabolic pathway and distribution of superparamagnetic iron oxide nanoparticles: In vivo study. Int. J. Nanomed. 2011, 6, 1793-1800.

184. Gu, L.; Fang, R.H.; Sailor, M.J.; Park, J.-H. In vivo clearance and toxicity of monodisperse iron oxide nanocrystals. ACS Nano 2012, 6, 4947-4954. [CrossRef] [PubMed]

185. Pouliquen, D.; Le Jeune, J.J.; Perdrisot, R.; Ermias, A.; Jallet, P. Iron oxide nanoparticles for use as an MRI contrast agent: Pharmacokinetics and metabolism. Magn. Reson. Imaging 1991, 9, 275-283. [CrossRef]

186. Weissleder, R.; Stark, D.D.; Engelstad, B.L.; Bacon, B.R.; Compton, C.C.; White, D.L.; Jacobs, P.; Lewis, J. Superparamagnetic iron oxide: Pharmacokinetics and toxicity. Am. J. Roentgenol. 1989, 152, 167-173. [CrossRef] [PubMed]

(C) 2019 by the authors. Licensee MDPI, Basel, Switzerland. This article is an open access article distributed under the terms and conditions of the Creative Commons Attribution (CC BY) license (http://creativecommons.org/licenses/by/4.0/). 